\title{
Music videos as meaningful entertainment? Psychological responses to audio-visual presentations of song narratives
}

Lea Margarete Schlue

Follow this and additional works at: https://researchrepository.wvu.edu/etd

\section{Recommended Citation}

Schlue, Lea Margarete, "Music videos as meaningful entertainment? Psychological responses to audiovisual presentations of song narratives" (2016). Graduate Theses, Dissertations, and Problem Reports. 6584.

https://researchrepository.wvu.edu/etd/6584

This Thesis is protected by copyright and/or related rights. It has been brought to you by the The Research Repository @ WVU with permission from the rights-holder(s). You are free to use this Thesis in any way that is permitted by the copyright and related rights legislation that applies to your use. For other uses you must obtain permission from the rights-holder(s) directly, unless additional rights are indicated by a Creative Commons license in the record and/ or on the work itself. This Thesis has been accepted for inclusion in WVU Graduate Theses, Dissertations, and Problem Reports collection by an authorized administrator of The Research Repository @ WVU. For more information, please contact researchrepository@mail.wvu.edu. 


\title{
MUSIC VIDEOS AS MEANINGFUL ENTERTAINMENT? PSYCHOLOGICAL RESPONSES TO AUDIO-VISUAL PRESENTATIONS OF SONG NARRATIVES
}

\author{
Lea Margarete Schlue \\ Thesis submitted to the Eberly College of Arts and Sciences \\ at West Virginia University \\ in partial fulfillment of the requirements \\ for the degree of \\ Master of Arts \\ in \\ Communication Theory and Research \\ Nicholas D. Bowman, Ph.D., Chair \\ Elizabeth L. Cohen, Ph.D. \\ Keith Weber, Ed.D. \\ Department of Communication Studies \\ Morgantown, West Virginia \\ 2016
}

Keywords: music videos, narrative transportation, narrative engagement, enjoyment, appreciation;

Copyright 2016 Lea Margarete Schlue 


\author{
Abstract \\ MUSIC VIDEOS AS MEANINGFUL ENTERTAINMENT? \\ PSYCHOLOGICAL RESPONSES TO AUDIO-VISUAL PRESENTATIONS
}

OF SONG NARRATIVES

by Lea M. Schlue

Combining auditive, visual, and textual elements in a unique way, music videos are currently one of the most popular and viral forms of entertainment media. Narrative music videos, in particular, engage their viewers by visually communicating the meaning of a song and its lyrics, which possibly employs them as a useful tool to communicate social, political and cultural messages to a broad audience, and implicates their social and cultural relevance. The purpose of this study was to test whether visual presentations of song narratives (as in music videos) foster a more transporting, engaging, enjoyable, and appreciative entertainment experience than listening to songs alone. Results disconfirm this notion. Songs by themselves were found to be more narratively engaging than in combination with music videos. Levels of enjoyment differed across transportation and engagement levels, but not across song presentations. Appreciation was both directly and indirectly related to song presentation. Practical implications and follow-up research are discussed. 


\section{ACKNOWLEDGEMENTS}

I would like to express my deep gratitude to my advisor Dr. Nicholas D. Bowman for his extraordinary commitment and mentorship. His useful comments, remarks, encouragement and engagement through the learning process of my master thesis helped me grow both academically and as a person. He is a true role model and has made a great impact in my life - I am honored to be able to call him my friend.

Furthermore I would like to thank Dr. Elizabeth L. Cohen and Dr. Keith Weber for their helpful feedback and support along the way. Also, I would like to thank the participants in my study, who have willingly shared their precious time. Finally, I would like to thank my loved ones in Germany - my parents in particular - who have always led by example and who have supported and encouraged me throughout this entire process, despite the distance and the obstacles it brings along. I will be grateful forever for your love. 
TABLE OF CONTENTS

ACKNOWLEDGEMENTS




\section{LIST OF FIGURES}

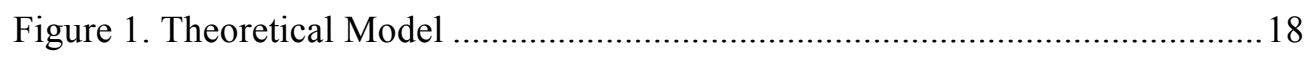

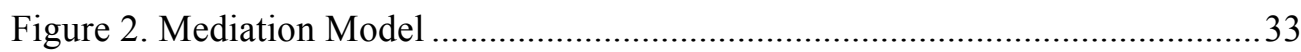




\section{LIST OF TABLES}

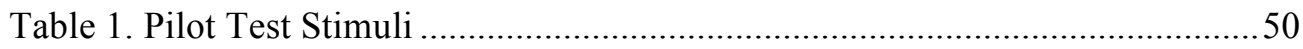

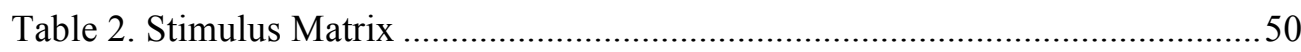

Table 3. ANCOVA (Transportation and Narrative Engagement) ...........................51

Table 4. ANOVA (Transportation and Narrative Engagement) ..............................51

Table 5. Linear Regression (Enjoyment) …...................................................... 51

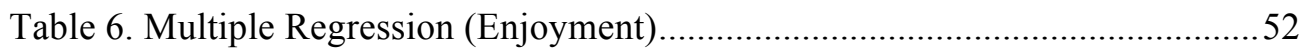

Table 7. Pearson Correlations (Narr Transp., Enjoyment) ......................................52

Table 8. Pearson Correlations (Narr Eng., Enjoyment) ...........................................53

Table 9. Linear Regression (Appreciation) ..........................................................53

Table 10. Multiple Regression (Appreciation) ……….........................................54

Table 11. Pearson Correlations (Narr Transp., Appreciation) .................................54

Table 12. Pearson Correlations (Narr Eng., Appreciation)......................................55 


\section{N T R O D U C T I O N}

Free online video platforms such as YouTube and VEVO are undeniably popular and maintain to be on the rise. In 2014, YouTube's one billion users watched a total of 4 billion videos daily. The topic most frequently searched for on YouTube is music. The number of online videos watched in the U.S. has increased more than 800\% between 2008 and 2014 (Petchers, 2014). The 10 most watched videos on YouTube are all music videos (Smith, 2015). The Recording Industry Association of America (RIAA) now ties music videos directly to the benchmark of a recording artist's success, by including video streams in their metrics for gold and platinum plaques (e.g., 100 video streams is equivalent to one song purchased; Petchers, 2014). Music video-based phenomena, such as numerous imitations of Korean recording artist $P S Y$ 's music video based Gangnam style dance moves (entering the keywords "Gangnam style dance" has over three million different search results on YouTube alone), do not only substantiate the popularity of music videos, but also show how they can capture people's attention.

With the launch of MTV in 1981, music videos quickly became accessible in over 22 million U.S. households and, as a consequence, gained popularity among a mainstream audience (Marks \& Tannenbaum, 2011). In line with the mainstream success, fear about negative effects of purportedly offensive music videos on the large teenage viewership began to take root and inspired several studies suggesting a correlation between music videos and violent behavior, sexual behavior, as well as race and gender attitudes of adolescents (Sherman \& Dominick, 1986; Cromie, 1989; Wallis, 2011; Frison, 2015). Indeed, these studies overall show a connection between the imagery displayed in the videos and inappropriate sexual attitudes and conduct. Certain music genres visualized in music videos, like hip-hop, gangster rap, and heavy metal, are found to have the strongest effect on teenagers and children, influencing their racial attitudes and interpersonal relations.

In response, recording artists defend their music videos (with or without explicit content) as artistically valuable. Beyoncé's self-titled album (2013), often referred to as “the visual album”, was released along with music videos for every single song on it, in order to better explain the true nature and 
meaning of the songs. She employed this strategy again with her 2016 Album release "Lemonade", also referred to as "the visual album", which was released as a 65 -minute long music video, consisting of several music videos blending into another, sampling the songs of the album, and thereby telling an ongoing, longer story.

"The visuals of the music video help me to show people the visuals in my brain, the story of the music. Connecting visuals to music makes it more of a body of work, it makes people hear the music differently.“(Beyoncé, 2013)

To the same effect, Pharrell Williams released the world's first 24-hours lasting music video for his song "Happy" (2014), portraying happy people in various settings throughout the entire day and night. A similarly new approach to music videos is the interactive music video, which allows viewers to individually interact with the music videos by changing the setting or controlling the character in it. Lynch (2014) argues that any of these recent approaches to music videos show that music videos can be seen as works of art. In addition to the described artistic value, an evolving number of popular mainstream recording artists use music videos as a way to reflect and raise awareness of cultural, societal, and political issues. In other words, they use music videos to communicate a pro-social message: Lady Gaga's music video for “Till It Happens To You” (2015) raises awareness of sexual assault on college campuses; M.I.A.'s music video for “Borders” (2015) addresses the Syrian refugee crisis; Beyoncé's music video for "Pretty Hurts" (2014) discusses the pressure on women to have outer beauty in society, and her music video for "Formation" (2016) reinforces the discussion on Black Lives Matter; Hozier's music video for "Cherry Wine" (2016) attempts to raise awareness of the issue of domestic violence; MTV has even established an award for the best video with a social message (Kaufman, 2015). It becomes apparent that branding music videos as a tool to promote promiscuous behaviors (the classic "sex, drugs, and rock 'n' roll" adage), is a rather narrow interpretation of a media form that seems to be much more complex than that. If anything, the given review indicates that music videos serve recording artists as an effective tool to not only express their music in innovative, multi-faceted ways, but also to communicate pro-social messages through their music. That is, the current study examines music videos 
in their role as an impactful, and meaningful entertainment. To empirically substantiate this point of view, the current study applies both narrative transportation theory and narrative engagement to examine ways in which music videos trigger a more engaging, enjoyable, and meaningful media experiences than songs alone. 


\section{R E V I E W O O F L I T E R A T U R E}

\section{Music Videos}

Before music television (MTV) was launched in 1981, music videos only occasionally aired on weekly pop shows on TV stations around the world, limiting their audience reach and ultimately their popularity. Music videos were described by various terms including "illustrated song", "filmed insert", "promotional film", "promotional clip", "promotional video", "song video", "song clip" or "film clip" (Railton \& Watson, 2011). The launch of music television, ironically introduced with the music video for "Video Killed the Radio Star" (The Buggles, 1979), is seen as essential in the recovery of a back then economically struggling music industry (Marks \& Tannenbaum, 2011). Nowadays, apart from actual music television channels, music videos are available for free streaming on online video platforms and embedded in websites and blogs dedicated to music and popular culture, as discussed in the introductory section of this paper. Once evolved, music videos became more intricate, complex, expensive, and dominant. In many music videos today, the visual aesthetics are both more expansive and expensive than the music production itself (Thompson, Graham, \& Russo, 2005).

Promotional Value. Music videos present customers with powerful consumption images and thereby influence customer culture (Englis, 1991). Music videos are seen as a more organic alternative for advertising than intrusive endorsement. Connecting songs with video elements, music videos, unlike TV or movies, can become a viral story - they can reach consumption and exposure levels that straight audio or straight advertising can hardly gain, which makes music videos very valuable to marketers (Bakula, 2014). Even the colloquial dictionary of record (Encyclopedia Britannica) defines music videos as "promotional film" (2015). This broad definition includes the common notion of music videos as a tool for music distribution (e.g., Fry \& Fry 1987; Kaplan 1987). Music videos help recording artists to attain new fans and to build new fan bases across different genres by visually representing the song and creating an actual image for the artist (Parr, 2006). In sum, music videos have an avowedly commercial agenda. 
By advertising another cultural form (music), the music video itself becomes more of a secondary product, which, on the downside, very much short-circuits the discussion of the value of music videos. In that sense, music videos are limited by some to the role of a marketing tool, only displaying the value of the song and the artist, other than adding value on their own. Notably, the current study challenges this myopic perspective, arguing that music videos can be important vehicles for experiencing the narrative of a song.

Artistic Value. In addition to their promotional value, music videos have been recognized as a significant, widely circulating, and interesting form of contemporary popular culture (Railton \& Watson, 2011). Music videos combine three media forms in a unique way: music (sound), lyrics (text) and visuals image; Keazor \& Wübbena, 2010) - as such, music videos have an ample aesthetical scope (Swallow 2003). Visual means are used to reveal musical structure and to underscore and highlight the song by reflecting the lyrics, apart from showcasing the recording artist (Vernallis, 2004). A wide range of styles of contemporary video making techniques, including animation, live action filming, documentaries, and non-narrative approaches such as abstract film, are being applied to music videos. Sometimes the different styles, such as animation, music, and live action, even blend into one another (Cutietta, 1985). Overall, it becomes apparent that music videos are more than just a promotional tool for music marketing. Music videos are aesthetically multifaceted and artistically valuable - a pop-cultural product, and a form of entertainment media. It is clear to see that attempts to define of music videos very much rely on links to other media and arts, as they are intrinsically linked. Keazor \& Wübbena (2010) take another perspective, arguing that music videos, then again, impact other media like film, art, and literature: writer Jasper Pforde was inspired by the cultural and narrative set changes in Michael Jackson's Music Video "Black and White" (directed by John Landis) for his book "Thursday Next". Additionally, the imagery of an Apple Inc. advertising in 2006 can be seen as a remake of the music video for "Such Great Heights" by the Postal Service (2003). What is more, Jesse Dylan (together with several other famous recording artists) produced a viral music video based on Barack Obama's famous "Yes We Can" speech from February 2008 to support his election campaign. In that sense, music videos even shape our everyday and 
political culture, which contributes to the overall argument that future media and communication research should include music videos as a culturally valuable and multifaceted entertainment media form, beyond its means for music marketing.

\section{Narrativity}

Although there are different types of music videos, the current study focuses on those music videos that tell a story - that is, those videos with a narrative. The presence of a clear and coherent narrative from a music video should intensify the experience of listening to music (when compared to listening to a song without video narrative elements) and inspire feelings of enjoyment and appreciation. Such an effect suggests that music videos are a meaningful media form beyond marketing, and can be meaningful beyond even the song itself. Therefore, the following paragraphs differentiate between the narrativity of song lyrics alone, and the narrativity of song lyrics in combination with motion picture that is, the narrativity of music videos.

Definition of narrative. Dependent on the context, narratives have been approached in a multitude of ways in philosophical and media psychology literature. According to Ranta (2013), there is overall agreement that (a) narrativity is matter of degree rather than kind, i.e. some narratives are more narrative than others, (b) narratives can be both literal and/or pictorial, and (c) perceptions of the same narrative may be individually different, because the storyteller and recipient share numerous unstated assumptions, including background knowledge of the narrative's lifeworld, the genre, and causal relationships among events, concepts of class, gender, age, and social roles. Thereby, narratives can be seen as a representation of possible worlds in a linguistic or visual medium (Fludernik, 1996, 2009). They create or provide miniature models of actual or fictional worlds in different degrees of detail and complexity, which can be achieved by multiplying the number of agents, events, and settings that are involved - including descriptions, expositions, arguments, and explanations (Ranta, 2013). Summarizing various functions stated in the body of literature, narratives are sources of education and entertainment, 
fostering empathy and knowledge - as they organize human experiences by constructing models of reality (Ryan, 2005). Stemming from these definitions, the current study summarized narratives as $a$ representation or account of experiences, events, or the likes. It can be true or fictitious, it is usually (but not exclusively) told in great detail, and it is designed to amuse, interest, or instruct.

Narrativity of music. Theoretical evaluations on the narrativity of music, for the most part, focus on non-lyrical, purely instrumental music such as classical piano compositions. Such approaches lends themselves to multiple philosophical views as to the narrativity of music. Overall, listeners are thought to mentally imagine, construct and attach narratives to instrumental music (Nattiez,1990; Abbott, 2002). Even though instrumental music does not contain any lyrics, they do have a narrative curve similar to those found in conversations, as there is often an introduction, development, climax, and concluding gesture (Childs, 1977). Referring to music in general (both instrumental and vocal songs), Ryan (2004) argues that listeners fill the musical plot with personal representations, which goes in line with the notion that people inevitably sense that songs tell a story, i.e. narrate (Vernallis, 2004).

Comparatively less research and theoretical evaluation has been conducted with regards to the narrativity of song lyrics, possibly because lyrics (and by extension, the process of songwriting) are seen as self-evidently narrative. Nicholls (2007) shows that the interaction of musical scores, lyrics and prose in popular music creates both single and multiple narratives in songs. His assumption is based on a musicological analysis of the song structure of The Beatles' "Norwegian Wood” (1968), Kate Bush's "Wuthering Heights" (1978) and The Buggles' "Video Killed the Radio Star" (perhaps ironically, the first music video to air on MTV when the network launched in 1981, although the song was released in 1979). Based on the observation that many people transcribe, post and read song lyrics on the internet, Moore (2012) further argues that the lyrics are the most important aspect of a song and that the popularity of songs consequently is based on its narrative. The narrative direction of songs is reinforced through the regularity of harmonic movement, which leads the listener from the beginning to the end of the song's narrative. Investigating the relationship of music and lyrics in popular songs, Middleton (1990) also argues for the narrativity of songs, stating that songs consist of affect (words as expression), story (words 
as narrative ) and gesture (words as sound). The reason for the narrow body of research on the narrativity of actual songs is that the songwriting and the textuality of the lyrics sung already indicate the inherently narrative character of songs - simply put, few argue that lyrics are not narratively engaging.

Music videos as multimodal narratives. Aufderheide (1987) refers to music videos as "the look of the sound", arguing that music videos visualize the story told through the lyrics - which speaks for the narrative potential of music videos. Narrative music videos further tell a story by forming an intimate relationship between the narrative of the video and the lyrical content of the song. They either literally narrate the story of the song, or portray a complete disjuncture between video narrative and lyrical narrative characteristics. Many of the images in music videos are directly motivated by the song and literally visualize the lyrics, and sometimes they even exceed the story of the song by providing plot details that are not present in the lyrics. Contributing to the implied notion that music videos are naturally narrative, Railton and Watson (2011) identify narrative music videos as one of four main genres of music videos (pseudo-documentary, art music video, narrative video, and staged performance). Jones (2011) even argues that any form of music video is communicating some sort of storyline to its audience, differentiating between mimetic narrative (i.e., the display of a in-concert performance of the song), analog narrative (i.e., visuals of the artist(s) performing the song in a non-concert context are intercut with other motion picture material), and digital narrative (i.e., the music video consists of motion picture material only, without any visuals of the actual performance of the song). Additionally, Vernallis (2004) argues that the narration through music videos is somewhat unique and differs from cinematic narration in terms of completeness and complexity: The story in music videos exists only in the relation between and combination of the song and the image it unfolds. The narration makes up for the lack of dialogue and that way keeps the music video recipient's attention, even if the music video does not narrate a full story but chooses imagery reflective of the particular form and scale of a pop song. What is more, music videos narrations can withstand non-causality and incompleteness: The music video for "Like a Prayer" (Madonna), for example, is narrative indeed but devotes little attention to questions of causality and completeness - to whether the murderer will be caught, whether Madonna will testify, or whether the 
saint will go free. Overall, it becomes apparent that music videos, at least a certain kind, can be construed as narrative.

In music videos, the perception of musical expression is created through a combination of visual information with the lyrics and melody of the song. The visual information provided in the music video catches a fair amount of the listener's attention (Bergeron \& Lopes, 2009), as the visual attention required by music videos fosters a more active and engaging way of song perception. Thus one can conclude that watching music videos probably offers a more emotionally and cognitively involving media experience than listening to a songs alone - narrative music videos presumably lead to a higher degree of narrative transportation and engagement than songs alone.

\section{Psychological Experiences of Narratives}

To understand the psychological experience of narratives, two related conceptualizations are evaluated in this study: Narrative transportation and narrative engagement, which are both empirically and conceptually highly related to one another (Busselle \& Bilandzic, 2009). The current body of research seems to resonate that narrative transportation refers to the specific theoretical conceptualization of how individuals mentally process narratives, and can be subordinated to the more broad concept of narrative engagement (e.g., Busselle \& Bilandzic, 2008 ; Green et al., 2004; van Laer et al., 2014; Slater \& Rouner, 2002). To reinforce this notion, Brechman (2010) even argues that transportation and engagement are causally related - the more engaging a story is, the more transporting it will be.

Narrative Transportation and Narrative Engagement. Narrative transportation (Green \& Brock, 2000) is facilitated by the narrative structure of entertainment media. It describes the emotional experience of mentally entering a mediated world, entailing a feeling of being swept up or lost in the narrative. Through narrative transportation, the mental systems and capacities fully focus on the narrative instead of the real world, which is often times accompanied by a loss of real-world facts, such as losing track of time. This experience usually entails mental imagery of the narrative as well as empathy with the plot and characters. The formation of mental imagery can be linked particularly to the high degree of 
detail in narratives, allowing story-receivers to experience both elevated emotional closeness with and greater knowledgeability of the story characters (Green \& Brock, 2000). Creating and updating these mental images, in the sense of narrative transportation, is a an unintentionally affective process. That is, during transportation, individuals do not thoughtfully evaluate and carefully consider the narrative storyline and messages therein in order to create mental images - which bring them cognitively and emotionally closer to the narrated world and likewise distances them from the real world. It presumably is the narrative structure itself that fosters this process, which is why the latter is supposed to be inherently unintentional. Rooting from the same standpoint of the absence of intentionality, but further specifying it, Busselle \& Bilandzic $(2008,2009)$ conceptualize the broader term narrative engagement, which includes the notion that in order to become fully mentally involved with a mediated narrative, as in transportation, individuals need to engage with the narrative - both cognitively and emotionally. For example, one has to process the motivation for breaking up (cognitively) as well as the feelings a break-up can cause (emotionally) in order to form mental images and be swept up into a story of the likes. That being said, narrative engagement (Busselle \& Bilandzic, 2009) provides a framework of the psychological experience during exposure to narrative entertainment media, that adds further dimensions to the classic narrative transportation approach. Narrative engagement further fleshes out the transportation-rooted dimensions of Attentional focus (the degrees of focus and distraction whilst engaging in the narrative), emotional engagement (sympathy for and empathy with the emotions of the character(s) within the narrative), narrative presence (transitioning from the real world to the narrated world), as well narrative understanding (making sense of and understanding the narrative, e.g. perspective taking). The latter, in particular, exceeds the theoretical framework of narrative transportation.

It becomes apparent that both conceptualizations - narrative transportation and narrative engagement - have been promoted in the investigation of the psychological and mental processes during narrative media consumption. In the current body of research, both scales have shown to be a crucial element to understand how individuals engage in different kinds of narratives. Even though the multilayered approach of narrative engagement can be argued to be somewhat augmenting the theoretical 
notion of narrative transportation, the latter is still the most broadly accepted and frequently employed approach in the context of narrative media experiences, (e.g., Slater \& Rouner, 2002; Green et al., 2004; van Laer et al., 2014). In reflection of this, the current study applies both approaches to gain an in-depth understanding of the narrative experiences of songs through different media modalities, as this specific context is a fairly specific and unexplored: Applying both approaches is thought to lead to more generalizable results, as it enables comparisons with previous research employing either engagement or transportation. It may further reveal similarities among (or differences between) the two conceptualizations in examining narrative experiences, giving new insight on how to best approach them in future research.

Transportation and Narrative Engagement through Music Videos. Green, Brock, and Kaufman (2004) argue that "the key psychological ingredients of the transportation experience are assumed to take place regardless of modality of communication" (p. 312). Green et al. (2008) found no difference in levels of transportation between narratives presented via film versus text. However, an evolving body of research suggests that differences in narrative media modalities are indeed able to influence individuals' levels of being immersed into a narrative: Strick, de Bruin, de Ruiter, \& Jonkers (2015) investigated the persuasive power of moving songs in audio-visual advertising, defining "moving" as intensely emotional and chills-evoking. Their experimental setting reveals that emotionally moving songs increased the experience of being swept up in the story of the advertising, resulting in a reduction of critical processing. Boltz (2004), and Marshall \& Cohen (1988) show that songs play a critical role in the individual way a viewer processes the narration of a film. What is more, findings by Lipscomb \& Kendall (1994) suggest that a film's soundtrack can provide more information about the narrative than a visual scene itself. Bullerjahn and Guldenring (1994) further found that the interpretation of a film scene can differ based on the soundtrack.

The described increase in levels of narrative transportation and engagement through the musical soundtrack needs critical revision: The observed effect may be due to the combination of the songs and 
the motion picture, not due to the musical score only. What is more, it is likely that motion picture without any music is less engaging and less transporting, as viewers expect motion picture to be accompanied by songs or at least some kind of musical piece throughout. The musical score in motion picture is often partially instrumental, i.e. non-vocal, and contributes to the motion picture. Overall the outlined body of research can foreshadow the increasing effect songs and soundtracks, i.e. musical scores, can generally have on the narrative transportation through motion picture, but it cannot really describe the unique combination of song and motion picture found in music videos. In music videos, the narrative visuals contribute to and are dedicated to the song, which basically turns around the logic of soundtracks contributing to visuals in movies.

More general research on multimodal narratives show that the formal properties associated with audio-visual material (its attention capturing and maintenance abilities), can increase accessibility of information from short-term memory, which then again can increase the likelihood of narrative transportation and engagement (narrative processing, i.e. understanding, in particular; Brechmann, 2010). Along these lines, matching visuals to verbal narratives has been found to increase perceptual fluency, which then again facilitated narrative understanding (as part of narrative engagement), as well as the generation of mental imagery (indicating narrative transportation; Chang, 2013). These findings reinforce the notion that multimodal narratives, i.e. the combination of visual and audio in narrative music videos, are able to heighten both narrative engagement and narrative transportation into visual narratives. In sum, it is assumable that music videos foster (a) a more narratively transporting and (b) a more narratively engaging entertainment media experience than listening to songs only.

H1a: Watching narrative music videos leads to higher levels of narrative transportation than listening to a song alone.

H1b: Watching narrative music videos leads to higher levels of narrative engagement than listening to a song alone. 


\section{Entertainment Outcomes of Narrative Media}

Narrative transportation (e.g. Nabi \& Krcmar, 2004; Raney \& Bryant, 2002) and narrative engagement (e.g. Soto-Sanfiel, 2015) can both help to understand and predict different entertainment outcomes. Enjoyment and appreciation, in particular, reflect the appraisal of the range of emotions experienced through narrative transportation during entertainment exposure, as well as of the emotional experiences resulting from that appraisal (Bartsch, Vorderer, Mangold \& Viehoff, 2008).

Enjoyment. Enjoyment can be defined as a pleasant state manifested not only in joy but also in experiences such as as serenity, sensory delight, achievement or suspense. It is based on an individual's beliefs, empathy with media content, motives for media use (e.g. escapism), as well as media technology. Various combinations of cognitive, affective, and behavioral information contribute to enjoyment, which may reference to both the media message and the media experience. Narrative elements in media are most likely to give rise to viewer enjoyment: Thereby some types of entertainment narratives are universally common (e.g. "happy end", "boy meets girls").

As concluded in preceding paragraphs, music videos seem to foster a more active, attentiongrabbing, and engaging song experience than listening to the song alone. The experience of being immersed in a narrative world significantly contributes to feelings of enjoyment (Green, Brock \& Kaufman, 2004). In other words, the process of narrative transportation and the overall experience of narrative engagement, as an experiences of cognitive, emotional, and imagery involvement in a narrative, are a significant predictor for enjoyment (Bilandzic \& Busselle, 2011). Goto (2007) further shows that enjoyment can result specifically from building mental models, as one aspect of narrative media experiences. Transportation theory further particularly suggests that enjoyment can benefit from the experience of being immersed in a narrative world, as well as from the consequences of that immersion (Green \& Brock, 2002): escaping the negative states and worries of the real world through narrative transportation entails the experience of positive states. Several correlational measures of transportation and enjoyment support these theoretical notions, showing that both scales tend to be highly correlated 
(correlation scores range from $r=.60$ to $r=.77$; Green, Brock, \& Kaufman, 2004). These correlation scores even suggest that transportation and enjoyment are empirically the same constructs. However, as outlined in previous sections, enjoyment and transportation are to be seen as two conceptually different constructs - at least in the current study, as reflected in the way of measurement.

Further, higher levels of narrative engagement have been found to increase enjoyment of both the content of the narrative entertainment media and the experience of consuming it (Green, Brock \& Kaufman, 2004; Bilandzic \& Busselle, 2011). Goto (2007), observes that song playback accompanied by visuals enables recipients to better immerse themselves in the music and therefore enjoy the song more (as without a visual component). Enjoyment of audio-narratives (audio books), to give another example, has been found to be resulting from specific engagement dimensions (identification with characters, perceived realism, narrative presence; Soto-Sanfiel, 2015), which indicates that the enjoyment of the mental experience of being engaged into the narrative of the media may override the enjoyment possibly resulting from the media itself. That is, if it is foremost the experience of being engaged and transported into the narrative that enhances positively valenced media responses to narrative media, other than the media content itself, visual presentations of songs, i.e. music videos, should be inherently more enjoyable - based on the theoretical assumption that they foster a more engaging and transporting media experience.

All in all, both transportation and narrative engagement, can clearly lead to enjoyment. If narrative music videos are truly more transporting and narratively engaging than music without complementary motion picture, the following can be assumed:

H2a: Greater levels of narrative transportation (through music videos) will lead to higher levels of enjoyment.

H2b: Greater levels of narrative engagement (through music videos) will lead to higher levels of enjoyment. 
Appreciation. Whereas enjoyment describes hedonic motivation and fun- and thrill-related gratification, appreciation rather refers to eudaimonic considerations resulting in meaningful gratifications of media exposure, such as a fulfillment of relatedness, and insight needs (Oliver et. al, 2015), as well as nostalgia, poignancy and elevation (Bartsch \& Oliver, 2010). Nostalgia, for example, is related to meaningfulness in the way that it is seen as a search for identity and meaning, connecting with others - it reflects both positive and negative elements, i.e. pleasant and unpleasant emotions. (Oliver \& Raney, 2011). In other words, appreciative audience responses do not indicate the absence or opposite of positive affect but mixed positive and negative affect (e.g. bitter sweetness) as well as meaningful cognitive components (introspection and contemplativeness). The experience of appreciation is a psychological appraisal process that is deliberate, slow and resulting from cognitive conflict (Lewis, Tamborini, \& Weber, 2014).

The appreciation of musical performances, in particular, has been found to be fostered when a song is accompanied by visuals (Platz \& Kopiez, 2012). Appreciation is depended on the individual perception and evaluation of a narrative (Oliver et. al, 2015) and it was argued in previous sections that visuals can very much can contribute to the experience of narratives through song lyrics, underscoring the story told. The music video for a song may even reveal the true intention or meaning of a song: narrative music videos of popular songs often times adopt surprisingly tragic, dramatic or traumatic themes, such as murder (e.g., "Breezeblocks" by Alt-J, or "Magnets” by Disclosure featuring Lorde), or rape (e.g. "Til it happens to you" by Lady Gaga, or "Man down" by Rihanna) which may not yet be apparent in the lyrics of the song alone. Watching such a music videos that portrays rape or murder, for example, is presumably less fun than the listening to the song itself, without this association. Nevertheless, those music videos are highly appealing to their audience. It can be assumed that these music video raise song appraisal beyond enjoyment - the music video possibly attributes meaning to the song and as such, it increases appreciation.

A recent finding by Oliver et al. (2015) on video games suggests an indirect relation between story ratings (as an indicator of individual perception and evaluation of narrative) and appreciation, which 
hints at a possible relation between narrative transportation and appreciation, or narrative engagement and appreciation. However, the causality of this possible relation remains rather unclear. The fact that appreciation is indirectly related to story ratings does not indicate if levels of appreciation would increase with increasing levels of narrative transportation and/or narrative engagement (through music videos), or not. $\mathrm{H} 1 \mathrm{a}$ and $\mathrm{H} 1 \mathrm{~b}$ forward that narrative transportation and engagement are higher for music videos than for listening to a song by itself, resulting in higher levels of enjoyment of music videos. If appreciation is as well an audience response resulting from engagement with and transportation into the narrative (a connection that has yet to be confirmed), it should likewise be higher for music videos than for songs only.

RQ1a: Do greater levels of narrative transportation (through music videos) lead to a higher appreciation (of music videos)?

RQ1b: Do greater levels of narrative engagement (through music videos) lead to a higher appreciation (of music videos)? 


\section{T H E O R E T I C A L M O D E L}

In sum, the literature review at hand suggests that a combination of both enjoyment and appreciation is likely to play an important role in the entertainment experience of narrative music videos. Both entertainment outcomes, enjoyment and appreciation, may result indirectly through the process of narrative transportation (H1a, H1b, H2a, H2b, RQ1a, RQ1b; see Figure 1).

However, numerous studies show a general positive effect of the visual component on the experience and evaluation of music (McPherson \& Thompson, 1998; Thompson et al., 2005). With this in line, an experiment by Ellis (2013) shows that there is a general difference in the preference between audio-only and audio-visual music listening, in favor of audio-visual music (i.e. music videos). Even though I argue for mediated effects explained through narrative transportation (theoretical evaluations suggest a mediated model, as discussed in the above sections), I acknowledge that there may also be a empirically direct effect between experiences of enjoyment and appreciation, and narrative music video exposure and take any direct effects into account when examining the data of this research study. The current study considers narrative transportation and narrative engagement as possible core mediators of the impact of narrative music videos on both enjoyment and appreciation - music videos are proposed to be more enjoyable and (potentially) more appreciated because their visuals foster levels of narrative engagement with the narrative, in line with narrative transportation into the narrative. 


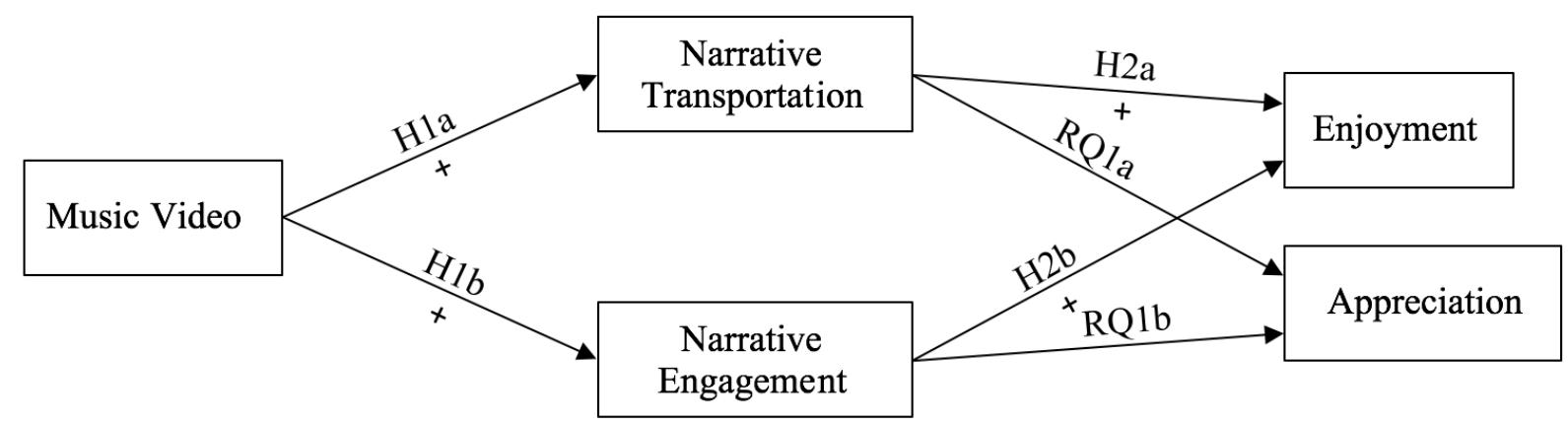

Figure 1. Theoretical Model: The proposed causal association between music videos, and enjoyment and appreciation outcomes, through narrative transportation and narrative engagement

\section{Co-Variates}

With regard to the theoretical model presented, there is reason to believe that further variables moderate or mediate the hypothesized effects. In order to evaluate the magnitude and strength of possible additional linear effects, the following variables have been taken into account.

Need for cognition. Need for cognition (Cacioppo, Petty \& Kao, 1984), refers to the natural enjoyment of (elaborative) cognitive effort, i.e. the individual's enjoyment of thinking. Individual differences in need for cognition have been argued to impact levels of narrative engagement and transportation (e.g., Green et al., 2008).

Need for affect. Need for affect is the degree to which an individual is motivated to seek out and engage in emotional experiences (Maio \& Esses, 2001). Both enjoyment and appreciation are experiences of feelings, i.e. affective media responses (Oliver et al., 2015). That is, need for affect may have a crucial impact on levels of enjoyment and appreciation.

Trait transportability. Transportability, as a trait, refers to an individual's trait tendency of being transported by narrative messages, based on the observation that there are individual differences in the deepness of transportation through narratives (Dal Cin, Zanna, \& Fong, 2002). 
State transportability. Green and Brock (2000) argue that some situations may make transportation more or less likely. More specifically, individuals in a boring or stressful state may long to be elsewhere and thus might be more motivated to transport themselves into a narrative.

Musical familiarity. It is possible that the participants' familiarity with the music may influence experiences of enjoyment or appreciation. To control for this effect, pre-existing media consumption of the stimuli chosen for this study (regarding artist, song, and music video) was accessed. 


\section{E T H O D}

\section{Data Collection}

Research Design. A randomized post-test control group design was implemented, exposing volunteer participants to one of three different music consumption conditions (explained in "Stimulus material" below). Additionally, an initial survey that evaluated stimulus-independent data (co-variates: trait transportability, need for cognition, need for affect; music habits, and demographics) was used to reduce the amount of questions in the post-test that followed the experiment (see Appendix B for all surveys).

Stimulus material. Participants were randomly exposed to one out of three presentations of a song: The song only (audio only; control condition), the narrative music video (original motion picture, complementary to the song), or the non-narrative video (novel motion picture, incongruent with the song). The three conditions were matched with either one of three different pilot-tested songs, resulting in a three-by-three experimental design, with overall nine different stimuli, randomly distributed among the participants, see Table 2. According to Puff (2015, p. 109), such varying stimulus material is an advisable way of ensuring that observed findings can generalize beyond a single stimulus, which can improve the study's generalizability.

Music Video Stimuli. Seven students from a small undergraduate communication class at West Virginia University were exposed to each of the nine different music videos (see Table 1, Appendix A). These were pre-selected based on the researcher's assumptions about the narrativity, sound- and picture quality, musical genre similarity, popularity (the latter was based on the amount of views on YouTube alone). The pilot test confirmed and specified similarities among the stimulus material and revealed the three most similar music videos with regards to rating of narrativity, emotional valence, musical genre, as well as video-and audio quality. Similarity among the level of narrativity was chosen as the most salient indicator, because levels of narrative transportation, apart from individual attributes, have been found to 
be strongly influenced by levels of narrative quality of the media (Green \& Brock, 2000; Dal Cin \& Zanna, 2004). Notably, in the current study, differences in narrative transportation and engagement - and resulting levels of enjoyment and appreciation - therefore should be able to be attributed to different presentations of songs (different stimulus conditions), other than different kinds of music videos (within the music video condition).

Resulting from the pilot test, primarily based on the narrative score and the familiarity among the sample, three different songs with their music videos were chosen: "Champion Sound" by Crystal Fighters (2010; pilot mean $M=5.75$ ), "Moaning Lisa Smile" by Wolf Alice (2015; pilot mean $M=5.50$ ), and "Indecision" by Shura (2016; pilot mean $M=5.60)$. None of these artists, songs, or music videos were previously familiar to the pilot sample.

The lyrics to the song "Champion Sound" describe how the singer moves to England, and does everything he wants with his friends, as they always did, without any regrets. He is dreaming about the things he hopes to be doing one day, such as being a successful musician. The music video thereby portrays a street musician that falls into some kind of hallucinating daydream as he starts playing his concertina, joining a group of flower people and trying to follow a beautiful girl that takes his hand but then disappears. He finds himself as a boxing champion in front of a cheering crowd, before he arrives back in reality. The sound can be described as a mix of musical elements of electronic, indie, folk, and pop.

The lyrics of "Moaning Lisa Smile" are about a girl that is struggling while trying to be happy and successful by pleasing other people. She becomes encouraged to do whatever feels best for her, i.e. to follow her own lead, in order to be happy and achieve her goals. The music video portrays a girl that is joining a local dance contest but is being rejected by all of the rehearsing dance groups. A group of crossdressed male dancers walk up to her. Together they form a new dance group that stuns the jury with their extraordinary and expressive performance. The genre of this song can best be described as pop-rock.

In "Indecision", the singer lyrically expresses feelings after breaking up with or having an argument with "her boy", telling him that she understands that he should take some time to figure out who 
he wants in life and that he has her love no matter what. The music video for the song shows a young man who is buying a necklace and visits a girl. They seem friendly, maybe a couple. However, the guy turns out to be a cross-dresser, or transgender, as both he and the girl enter a club after dressing up and putting makeup on. They meet their friends, and all people in the club dance together friendly - independent of male, female, or transgender. The sound can be described as indie-synth-pop.

Non-Narrative Video Condition. This video only adds the visual motion picture element to the song, neither interfering with nor contributing to the song narrative. In other words, it adds visuals but does not add complementary narrative to the song. This comparative treatment allows to confirm (or disconfirm) that the levels of narrativity (or: narrative elements), other than the visuals themselves, impact the psychological outcomes measured in the current study. The video was selected based on the conditions to be (a) a motion picture, and b (b) narratively neutral to the song lyrics. The visuals of a fairly unknown, publicly available video were chosen, (URL: http://bit.ly/24LMTq5, uploaded 15 Feb 2011, 440 clicks on YouTube as of May 2016), showing car ride through a non-identifiable city at night that was overlaid with an artistic, blurry filter, from the driver's perspective (original length: 5:59; cropped to stimulus songs accordingly - 3:35, 3:55, 2:47). This video was paired up with the same audiooutput used in the other conditions.

Song-Only Control Condition. It has been argued that songs are inherently narrative, and that music videos add additional visual narrative elements to the song, which may be complimentary with the song narrative. To be able to confirm or disconfirm the argument that music videos are more narrative than songs alone, a third condition controls for the natural non-visual song condition (audio listening only). An audio-only file for each of the three songs has been created from the music video output to ensure that the audio content, length, and quality was identical in all study conditions.

\section{Participants}

A sample of 129 undergraduate students completed both the online survey session and the experimental procedure session in the lab. Students were offered course credit by their instructors and 
recruited from four different communication courses at WVU, which typically represent students with a variety of majors and study levels. A total of 12 participants were excluded from the analysis as their experimental survey could not be matched up with the initial survey, resulting in an analysis sample of $\mathrm{N}$ $=117$ (53 male, 63 female, 1 transgender; age average of 21.53, $S D=2.49$ ). As far as music habits were concerned, participants indicated to mostly listen to Hip-Hop \& Rap $(M=6.02, S D=1.25)$, Pop $(M=$ $5.75, S D=1.1)$ and $\mathrm{R} \& \mathrm{~B}(M=5.50, S D=1.2)$, with a daily song listening median of 111.43 minutes $(S D$ $=147.55)$, and a daily music video watching median of 2.86 minutes $(S D=34.28)$.

\section{Procedure}

As announced in class (by the researcher) and on eCampus (through the instructor), students received the link for the initial survey via email. Students were informed by the instructor that completing both the initial questionnaire and the lab session, would result in extra credit, which functioned as an incentive and motivation for students to participate. Participants were asked to include their email address at the end of each survey, so that both surveys could be matched, for data analysis purposes only. The initial survey included a link to the Communication Studies Communication Research Participation Registration (https://wvucomm.sona-systems.com), for students to anonymously sign up and schedule for the experiment. In that sense, date and time of participation were scheduled in advance, based on the the subjects availability in a given time frame. Subsequently, participants were invited to a media lab, and randomly assigned to one of the three experimental conditions (song-only, original music video, songneutral music video) upon their arrival in the lab. Prior to taking the survey, participants were briefly informed about the study and signed a minimal-risk experimental consent form (required by the American Psychological Association's (2002) ethical guidelines). The study was approved by the institutional review board (IRB) at West Virginia University (Protocol \#1602018917).

Experimental setup. Each participant has been single seated in one of three identical cubical booths, with a digital survey set up on a computer screen. The booth prevented participants from seeing each other or otherwise interacting with each other while taking the survey. Participants were asked to 
follow the instructions on the computer screen. The first instruction (on screen) was to put on noisecancelling headphones on, which were located in front of the participants, on the computer desk, and already plugged into the computer, set at a comfortable medium volume. The setup and type of headphone was identical for all participants. This set-up ensured that all participants listened to the songs in the same audio output quality and volume. The noise-cancelling headphones further prevented participants from interacting with each other, and allowed them to fully focus on the song or music video content. This was an important aspect in testing the proposed theory, as distractions could further reattract attention to the real world rather than the media world which prevents readers from being fully immersed in a narrative world, possibly reducing media enjoyment (Green \& Brock, 2000; Green, Brock, \& Kaufman, 2004). Participants were further asked to silently keep seated in their cubicle until the researcher gave a sign that everyone in the room was finished with filling out the survey. This step was taken to further prevent participants to distract one another by picking up their belongings and leaving the room.

\section{Measures}

Rating of Narrativity. Identically with the pilot test, narrative score was evaluated through a self-designed measure, asking participants to to rate how much they agree with the following statement on a 7-point likert-type scale: "A narrative is a representation or account of experiences, events, or the likes. It can be true or fictitious, it is usually (but not exclusively) told in great detail, and it is designed to amuse, interest, or instruct." - with regard to the song they just listened to, or watched $(M=4.60, S D=$ $1.60)$.

Narrative Engagement. Engagement in the song narrative was measured through the 12 -item narrative engagement scale, as developed based on elements of the transportation scale (Green \& Brock, 2000) and identification scale (Cohen, 2003), by Busselle and Bilandzic (2009). The phrasing of the items was adapted to engagement with song, in all three conditions. The scale consists of of the four theorybound subscales: narrative understanding (e.g. "At points, I had a hard time making sense of what was 
going on in the song", reverse coded) attentional focus (e.g. "I found my mind wandering while the program was on." , reverse coded), narrative presence (e.g. "The song created a new world, and then that world suddenly disappeared when the program ended."), and emotional engagement (e.g. "During the song, when a main character succeeded, I felt happy, and when they suffered in some way, I felt sad.”).

The first 6 items were reverse scored and re-coded accordingly. The scale showed excellent internal consistency $(\alpha=.88, M=3.66, S D=1.33)$.

Narrative Transportation. The Transportation Scale (Green \& Brock, 2000) was comprised of 11 items measuring the individual's attention and emotional reactions to the media consumed. The language on the scale items was slightly adapted to reference music, for both the song-only condition (e.g., "While I was reading the narrative" was changed to "While I was listening to the song") and both music video conditions (e.g., "While I was watching the music video"). Further sample items include "I was mentally involved in the song while listening to it" and "I found myself thinking of ways the song could have turned out differently". The transportation measure was scored on a 7 -point Likert scale $(1=$ Strongly disagree to $7=$ Strongly agree), with three reverse-scored items. In the current study, the transportation scale ( 11 items) showed an unacceptable internal consistency $(\alpha=.64)$. To increase the internal consistency, one item ("While I was watching the music video, activity going on in the room around me was on my mind.", reverse coded) was deleted from the scale, resulting in an acceptable internal consistency of $\alpha=.73(M=3.73, S D=.99)$.

Whereas the narrative engagement items always referred to the song narrative in general, independent of the condition, narrative transportation items referred to watching the music video in the music video conditions and refers to listening to the song in the song-only condition. In other words, the two scales measured two different things in this study: Whereas the engagement scale measured how narratively immersed people were into the song, throughout three different presentations of the song, the transportation scale measured how narratively immersed people were while watching a music video (song-complementary or non-narrative) versus while listening to music (audio only). Thus, for all subsequent data analyses, the two constructs were considered conceptually independent measures. 
Enjoyment and Appreciation. To rate enjoyment and appreciation of the experimental stimulus, the audience response scale (Bartsch \& Oliver, 2010) was included, and recorded on 7-point scales ranging from 1 (strongly disagree) to 7 (strongly agree). The scale measures both enjoyment and appreciation and consists of 15 items selected to represent fun, suspense, moving/thought-provoking experience, and lasting impression, as well as items measuring perceptions of artistic value. Twelve items on the scale can be computed into four dimensions: (1) fun ("It was fun for me to watch this movie", "I had a good time watching this movie", "The movie was entertaining"), (2) suspense ("I was at the edge of my seat while watching this movie", "This was a heart-pounding kind of movie", "The movie was suspenseful"), (3) moving/thought-provoking experience ("I found this movie to be very meaningful", "I was moved by this movie", "The movie was thought provoking") and (4) lasting impression ("This movie will stick with me for a long time", "I know I will never forget this movie", "The movie left me with a lasting impression"). Whereas all four dimensions overall emerge from theoretical conceptualizations of enjoyment and appreciation, only the fun dimension, in particular, was empirically associated with enjoyment, and the moving/thought-provoking dimension, on the other hand, with appreciation. That is, for the purpose of the current study, enjoyment has been accessed via the fun dimension only (three items, $\alpha=.95, M=4.78, S D=1.70)$, and appreciation via the moving/thought-provoking dimension only (three items, $\alpha=.83, M=3.67, S D=1.46$ ). The phrasing of the items of the scale was slightly adapted to refer to songs, independent of the stimulus condition (e.g. "I was moved by this song").

Need for cognition. Need for cognition was measured with the 18-item, 7-point need for cognition scale (Cacioppo, Petty \& Kao, 1984), rating the extent to which individuals agree with statements about the satisfaction they gain from thinking, with items such as "I really enjoy a task that involves coming up with new solutions to problems" and "Thinking is not my idea of fun" (reverse scored). Nine items were reverse scored and re-coded accordingly. The scale showed excellent internal consistency $(\alpha=.91, M=4.48, S D=.94)$.

Need for affect. To access need for affect, participants responded to the 25 -item Need for Affect Questionnaire (NAQ-S; Maio \& Esses, 2001), which measures the extent to which individuals agree with 
statements about emotions when reflecting on their own enjoyment of and preference for experiencing emotions and emotional media messages. Scale items include "I would prefer not to experience either the lows or highs of emotion" and "It is important for me to know how others are feeling.". The second half of the scale (12 items in total), was reversed scored and re-coded. The scale showed excellent internal consistency $(\alpha=.87, M=4.44, S D=.79)$.

Transportability. For trait transportability, participants were asked to generally reflect on watching their favorite television show or movie, listening to their favorite music, reading their favorite book, or playing their favorite video game, when responding to the 18 item, 5-point Likert transportability scale (Dal Cin, Zanna, \& Fong, 2002). Items include "I can easily envision the events in the story" and "I sometimes feel as if I am part of the story". After re-coding three reverse-scored items, the current study found excellent internal consistency $(\alpha=.87, M=4.85, S D=.73)$ for this measure.

As indicated, situational feelings of boredom or stress may further influence the likelihood of narrative transportation. There is no given scale for such state transportability, which is why responses to four items on the level of stress and boredom during and before the experiment were gathered on a 5point scale. However, this scale was assessed at the end of the experimental survey, that is, after 5 minutes of filling out scales (i.e. five minutes passed since stimulus exposure). This gives reason to believe that the two items referring to the current state ( "I feel bored right now." and "I feel stressed right now.") hardly represent the transportability level during listening to or watching the song. If anything, they reflect on the feelings about filling out the survey - which is not of interest for this study. Therefore, only two items for state transportability are retained for further analysis, both referring to the state of boredom or stress during the entire day up until the point of answering the questions ("I have felt bored all day." $M=2.81, S D=1.52$, ; "I have felt stressed all day." $M=3.30, S D=1.76$,). As these items further showed unacceptable internal consistency $(\alpha<.7)$ and only a small significant correlation $(r=.32)$, these two state transportability items were treated as two individual covariates in the following analyses. 
Demographics. Participants were asked to indicate gender, ethnicity and age, and their music habits (rating of genres, daily music listening average). Due to the setup of this study, all participants necessarily were currently enrolled undergraduate college students and at least 18 years old. 


\section{R E S U L T S}

\section{Stimulus Check}

In order to check if the pilot test results of the chosen stimuli carry over to the actual sample of this study, ratings of narrativity among the three music video conditions were measured (Champion Sound: $M=4.07, S D=1.90$; Indecision: $M=3.69, S D=1.80$; Moaning Lisa Smile: $M=3.57, S D=$ 1.90). An analysis of variance (ANOVA) confirmed that the narrative scores did not differ significantly across the three songs, $F(2,38)=.73, p=.76, \eta 2=.01$. A Tukey post-hoc test further confirmed that all three songs build only one subset. Consequently, all post-test survey scores across the three songs were collapsed in terms of the media modality experimental condition, leading to three comparison groups (song only, $n=39$; music video, $n=41$; song-neutral video, $n=37$ ).

\section{Hypothesis Testing}

Narrative Transportation. Hypothesis H1a forwarded that levels of narrative transportation differ along stimulus conditions, with narrative music videos leading to higher levels of narrative transportation than songs alone. Results of a analysis of variance (ANOVA) revealed that narrative transportation was not significantly affected by the stimulus condition $(F(2,116)=1.75, p=.18, \eta 2=$ .03). Therefore H1a was rejected. Additional results of an analysis of covariance (ANCOVA) revealed that need for cognition $(F(2,116)=7.50, p=.01, \eta 2=.06)$, and need for affect $(F(2,116)=6.69, p=.01$, $\eta 2=.06)$, as well as state transportability levels of boredom $(F(2,116)=6.36, p=.01, \eta 2=.06)$ and stress $(F(2,116)=4.34, p=.04, \eta 2=.04)$, all had a significant effect on levels of narrative transportation (see Table 3, Appendix A, for complete ANCOVA results).

Narrative Engagement. Hypothesis $\mathrm{H} 1 \mathrm{~b}$ forwarded that levels of narrative engagement differ along stimulus conditions, with narrative music videos leading to higher levels of narrative engagement than songs alone. Results of an analysis of variance (ANOVA) revealed that narrative engagement did 
differ significantly across the stimulus conditions $(F(2,114)=4.80, p=.01, \eta 2=.08)$. A closer examination of the means revealed that the song-only condition $(M=4.09, S D=.89)$ led to the highest levels of narrative engagement (music video condition: $M=3.37, S D=1.24$; song-neutral video condition: $M=3.53, S D=1.13$ ), which contradicts $\mathrm{H} 1 \mathrm{~b}$ and led to the rejection of this hypothesis. A pairwise comparison further revealed that only the song-only condition and the music video condition were significantly different from one another $(M D=.60, S E=.24, p=.05)$. As far as covariance was concerned, an additional analysis of covariance (ANCOVA) revealed that state transportability levels of boredom $(F(2,116)=7.73, p=.01, \eta 2=.06)$ significantly affected levels of narrative engagement (see Table 3, Appendix A, for complete ANCOVA results).

Enjoyment. Hypothesis H2a forwarded that greater levels of narrative transportation will lead to higher levels of enjoyment. Using multiple regression, enjoyment scores were regressed on the linear combination of six independent variables in two blocks. Block 1 included the covariates of transportability, need for cognition, need for affect, level of boredom, level of stress. Block 2 included the target independent variable of narrative transportation. The overall regression model was significant, $F$ $(6,110)=5.07, p<.001$, and accounted for $18 \%$ (adjusted $R 2)$ of the variance in enjoyment, with the addition of narrative transportation accounting for $14 \%$ of this variance $(R 2$ change $=.14, p<.001)$. A closer examination for the beta weights in Block 2 revealed that only narrative transportation $(\beta=.42, p<$ .001) was a significantly related to enjoyment; none of the covariates showed significance. An additional linear regression (enjoyment scores regressed on narrative transportation only) showed that narrative transportation alone accounted for $16 \%$ of the variance in enjoyment (see table 5 for all linear regression results).

Hypothesis $\mathrm{H} 2 \mathrm{~b}$ forwarded that greater levels of narrative engagement will lead to higher levels of enjoyment. Using multiple regression, enjoyment scores were regressed on the linear combination of six independent variables (covariates: transportability, need for cognition, need for affect, level of boredom, level of stress; narrative engagement). The equation accounted for $44 \%$ (adjusted $R 2$ ) of the variance in enjoyment $(F(6,110)=16.29, p<.001)$, with $R 2$ change $=.40$. A closer examination of the 
beta weights revealed that only narrative engagement $(\beta=.67, p<.001)$ was significantly related to enjoyment (see Table 6-8, Appendix A, for complete multiple regression results and correlations on enjoyment for both hypotheses). An additional linear regression (enjoyment scores regressed on narrative engagement only) showed that narrative engagement alone accounted for the previously found $44 \%$ variance in enjoyment (see table 5, Appendix A, for linear regression results on enjoyment for both hypotheses).

Appreciation. RQ1a was concerned with greater levels of narrative transportation leading to higher levels of appreciation. Using multiple regression, appreciation scores were regressed on the linear combination of six independent variables (covariates: transportability, need for cognition, need for affect, level of boredom, level of stress; narrative transportation). The equation accounted for $22 \%$ (adjusted $R 2$ ) of the variance in appreciation $(F(6,110)=6.48, p<.001)$, with $R 2$ change $=.15$. A closer examination for the beta weights revealed that only narrative transportation $(ß=.43, p<.001)$ was a significantly related to appreciation. An additional linear regression (appreciation scores regressed on narrative transportation only) showed that narrative transportation alone accounted for the previously found $22 \%$ variance in enjoyment in the tested model.

RQ1b was concerned with greater levels of narrative engagement leading to higher levels of appreciation. Using multiple regression, appreciation scores were regressed on the linear combination of six independent variables (covariates: transportability, need for cognition, need for affect, level of boredom, level of stress; narrative engagement). The equation accounted for $52 \%$ of the variance in appreciation $(F(6,110)=21.96, p<.001)$, with $R 2$ change $=.43$. A closer examination for the beta weights revealed that both need for affect $(\beta=.15, p=.03)$, and narrative engagement $(ß=.70, p<.001)$ were significantly related to appreciation (see Table 10-12, Appendix A, for complete multiple regression results and correlations on appreciation for both hypotheses). An additional linear regression (appreciation scores regressed on narrative engagement only) showed that narrative engagement alone accounted for the previously found 52\% variance in appreciation in the tested model (see table 9, Appendix A, for linear regression results on appreciation for both hypotheses). 


\section{Mediation Analysis}

To this point, my hypotheses and research questions only investigated direct effects of media modality on narrative transportation and engagement $(\mathrm{H} 1)$, and the effects of narrative engagement on enjoyment and appreciation (H2 and RQ1). However, a core focus of this thesis is to understand the impact of media modality both (a) directly on entertainment outcomes and (b) indirectly on entertainment outcomes, as mediated through narrative transportation and engagement. Given that no direct effect of media modality on narrative transportation was observed, and that a significant difference in narrative engagement was observed between the song-only and original music video conditions (such that songs fostered a greater sense of narrative engagement than videos), two mediation models (one for each entertainment outcome) were tested comparing songs (coded as "1") to original music videos (coded as “0”). Both models were analyzed using the PROCESS macro for SPSS (Hayes, 2016). Both models are discussed and presented below (Figure 2), including the combined model. Notably, the analysis confirmed the direct effects found in $\mathrm{H} 1 \mathrm{~b}$ - condition was a significant predictor of narrative engagement such that songs were seen as more narratively engaging that music videos, $b=.73, p=.01$.

Enjoyment. The analysis further confirmed $\mathrm{H} 2 \mathrm{~b}$, in that narrative engagement was significantly related to enjoyment, $b=1.02, p<.001$. However, neither the total effect nor the direct effect between media modality of song presentation and enjoyment were significant, see Figure 2 . That is, enjoyment neither results directly from condition, nor indirectly through narrative engagement.

Appreciation. The analysis confirmed previous findings for RQ1b (narrative engagement was a significant predictor of appreciation, $b=.80, S E=, p<.001)$. Further, a total effect between condition and appreciation was found to be significant ( $b=1.07, S E=, p<.001$ ) has been found. In addition, the analysis revealed a direct effect between condition and appreciation, $b=.50, S E=, p<.001$. That is, 
there is both a direct and indirect effect with appreciation, which at the same time eliminates the theoretically proposed mediation. The complete model is included in Figure 2.

Indirect and total effects:

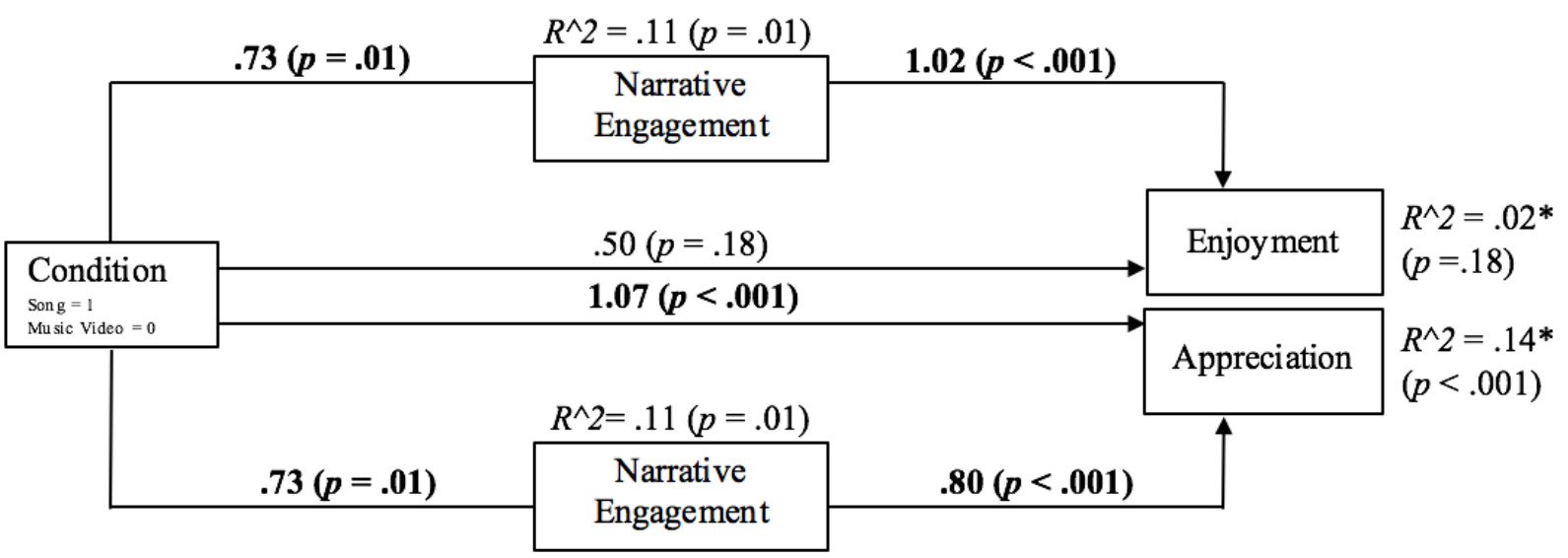

${ }^{*} R^{\wedge} 2$ here is the partial $R^{\wedge} 2$ accounted for directly by media modality condition

Direct effects:

\begin{tabular}{|c|c|c|c|}
\hline \multirow{2}{*}{$\begin{array}{l}\text { Condition } \\
\text { Son } \mathrm{g}=1 \\
\text { Mu sic Video }=0\end{array}$} & $-.24(p=.42)$ & \multirow{2}{*}{ Enjoyment } & \multirow{2}{*}{$\begin{array}{l}R^{\wedge} 2=.46 \\
(p<.001)\end{array}$} \\
\hline & & & \\
\hline \multirow{2}{*}{$\begin{array}{l}\text { Condition } \\
\text { Song }=1 \\
\text { Music Video =0 }\end{array}$} & $.50(p=.04)$ & \multirow{2}{*}{ Appreciation } & $R^{\wedge} 2=.51$ \\
\hline & & & \\
\hline
\end{tabular}

Figure 2. Mediation Model: indirect, total, and direct effects 


\section{I S C U S S I O N}

This study examined levels of enjoyment and appreciation of different audio-visual presentations of songs, through narrative engagement and transportation. This approach was based on the assumption that visual narratives (as in music videos) would lead to higher levels of narrative engagement and narrative transportation, which in turn would lead to higher levels of of enjoyment and appreciation resulting from music videos (i.e., visual-audio), in comparison to songs only (i.e. audio only). The second link in the proposed theoretical model (the relation between levels of narrative engagement and transportation and mixed-valenced audience responses) was reflected in the data analysis as expected, reinforcing the current body of research. However, the first link, proposing higher levels of narrative engagement and transportation through visual presentations of songs, was not confirmed. Indeed, the current study found the opposite effect. Each of these observations is discussed below, as well as their practical and theoretical implications.

\section{Enjoyment and Appreciation}

Findings from both Hypothesis $\mathrm{H} 2 \mathrm{a}$ and $\mathrm{H} 2 \mathrm{~b}$, confirming higher levels of enjoyment through narrative engagement and narrative transportation, are consistent with the existing body of research (e.g. Green, Brock \& Kaufman, 2004; Bilandzic \& Busselle, 2011). However, enjoyment was only significantly linked to narrative transportation and narrative engagement, but neither directly nor indirectly resulting from stimulus exposure, i.e. listening to or watching a song. That is, enjoyment, in the current study, presumably resulted from the media experience (the content on-screen or in the headphones), rather than the media modality itself. The current study further confirms that appreciation, as an audience response, can be related to both higher levels of narrative engagement and transportation, as well as stimulus exposure. As no mediation effect of appreciation resulting from song condition 
through narrative engagement has been found, current findings suggest that appreciation independently results from both, the musical content, and the experience of being narratively engaged.

Interestingly, need for affect was further found to foster appreciation. This finding contradicts the need-based approach to appreciation (Vorderer, 2009), which argues appreciation to be a higher order rational need that clearly distinguishes from emotional needs. Notably, appreciation was operationalized through concepts of meaningfulness, being moved, and provoking thought (Busselle, \& Bilandzic, 2009). These concepts relate to strong (rather negative) emotions and personal significance, which makes them inherently affective. In fact, the current findings confirm more recent empirical approaches to media appreciation (e.g., Lewis et al., 2014, Oliver et al., 2015), arguing that appreciative media responses are inherently affective - appreciation represents a continuum of emotions (other than just contradicting enjoyment), and further reflects both the appraisal of emotions experienced during immersive narrative entertainment exposure, as well as of the emotional experiences resulting from that appraisal (Bartsch, Vorderer, Mangold \& Viehoff, 2008).

\section{Narrative Transportation}

Individual levels of narrative transportation did not differ between different presentations of songs, i.e. were not found to differ based on different media modalities. This finding contradicts theoretical assumptions that visualizations of narratives are generally more transporting, i.e. more likely to cause individuals to become mentally swept up in the narrative, as they are thought to provide a more attention-grabbing and rich media experience (e.g., Bergeron \& Lopes, 2009). However, none of these previous studies refer to songs or music videos, who were argued to combine audio and visual in a very unique way - with visuals contributing detail and meaning to the story inherently told through the lyrics, other than the visuals leading the narrative, as in movies, for example. The finding that music videos did not lead to higher levels of self-reported narrative transportation, however, implies that the process of mentally entering a story narrated through a song may simply be independent of the media modality presenting the narrative (as also argued by Green, Brock, and Kaufman, 2004; Green et al., 2008). In 
other words, when it comes to song narratives, audio-visual media elements do not foster a more transporting experience. The fact that participants were specifically asked about watching the music video and listening to the song in the respective stimuli conditions, when responding to the narrative transportation scale, further encourages this notion: They referred to their experience with regard to the specific media modality - other than the story of the song particularly - but still did not report differences in narrative transportation. Keeping in mind that the experience of transportation usually entails mental imagery of the narrative as well as empathy with the plot and characters, linked to the high degree of detail in narratives (Green \& Brock, 2000), it can be argued that music videos simply do not fulfill these characteristics and therefore do not contribute to narrative transportation on top of the levels of narrative transportation given through the song alone. In fact, music videos were overall not perceived as highly narrative (the rating of narrativity of the music videos remained overall neutral on a 7-point Likert scale, see Manipulation check).

That being said, it is important to take into account that the experience of knowledgeability of story characters and elevated emotional closeness with them plays a crucial role when it comes to narrative transportation (Green \& Brock, 2000). It can thus be assumed that presentations of songs, through different media modalities, simply do not allow for meaningful character attachment of this kind. If anything, it can be argued that individuals almost inevitably fill the musical plot with their own experiences (e.g., Ryan, 2004), independent of the its presentation (audio or audio-visual). In other words, when it comes to songs, people may much more personally identify with the narrative, other than experience the narrative through an identifiable character (through which narrative transportation has been evaluated - at least partially).

\section{Narrative Engagement}

In line with propositions about narrative transportation, narrative engagement was thought to be higher after exposure to the narrative music video in comparison to song listening only. Levels of narrative engagement based on the narrative music video and the song-neutral video were not found to be 
significantly different from one another, but were found to differ significantly between the narrative music video and the song-only condition. As the original music video stimuli arguably narrated a storyline coherent with the song lyrics, whereas the song-neutral video simply provided neutral visuals that stood in no particular relation to the song lyric narrative, similarities in narrative engagement can likely be referred back to the media modality that they have in common (music combined with video). As stated, the third condition - song audio only - did differ significantly from the two visual conditions. In sum, the current research reinforces the theoretical core notion that differences in narrative engagement can be based on differences in media modalities.

However, contradictory to former theoretical assumptions, the non-visual song-only condition let to higher levels of narrative engagement. Notably, narrative engagement was evaluated in reference to the song, throughout all conditions, and partially conceptualized as narrative understanding - which is asking participants to report on the degree to which they were able to grasp and process the narrative (Busselle, $\&$ Bilandzic, 2009). The finding that people who were exposed to the audio of the song, and asked to indicate their levels of narrative engagement with this song, did score higher in engagement than those who were asked to report their engagement with the song, referring to a music video of the song, leads to two different assumptions: Participants in the music video condition were either (a) overall less narratively engaged, or (b) just as narratively engaged - or even more narratively engaged - but with the music video instead of with the song itself, and therefore indicated lower levels of narrative engagement with the song. Assumption (b) implies that the music video was perceived as something different than the song, because if participants would have perceived the music video as being a representation or expansion of the song, they should have referred to the music video with the similar levels or with higher levels of narrative engagement (due to the theoretical engagement-enhancing qualities of visuals), as they have with the song alone. That is, in terms of assumption (b), the results of this study regarding narrative engagement can be attributed to a methodological artefact based on the phrasing of the items in the narrative engagement scale. They further hint at the previously discussed phenomenon that music videos and songs are perceived as two different stories, i.e. seemingly do not contain the same narrative. The 
following paragraphs suggest three different explanations for the phenomenon that visual song presentations were less narratively engaging then listening to the song alone: distraction, mental overload, and lack of motivation.

(1) The visual narrative may have been dissonant to the mental images people created about the song-narrative, which caused distraction from the experience of mentally entering and processing the song. That is, whereas the the narrative music video imposed a narrative upon participants, the song-only condition told the narrative they mentally attached to it while listening, based on personal representations relating to the lyrics and/or the emotions they evoke (in line with notions by Ryan, 2004, and Vernallis, 2004). Personal mental representations made the song-only condition inherently more engaging and emotionally rewarding. The visual narrative in the music video condition, on the other hand, was likely not in line with the highly individualized mental images of the participants and therefore led to less narrative engagement.

(2) Participants encountered a mental overload when handling both the visual narrative and their own mental images of the narrative at the same time, which reduced narrative engagement. This notion goes in line with the Limited Capacity Model of Motivated Mediated Message Processing (LC4MP; Lang, 2000), which, in its very basic notion, states that an individual's cognitive and attentional bandwidth is restricted, as the processing of and engagement with information received through the media is automatically controlled by an appetitive and aversive cognitive sub-process that takes care of sensor stores in the brain.

(3) The visual narrative elements provided in the music video have possibly been perceived as un-necessary to follow the song's narrative, which inherently only requires attentive listening. That is, participants simply may have had a lack of motivation to use additional resources to become mentally involved with the song's visualization, and thus purposefully restricted the allocation of valuable mental resources, which would be necessary to process the multi-modal (and therefore somewhat multi-layered) narrative of the music video. This explanation goes in line with the notion of cognitive misers, i.e. the valuation of mental processing resources which leads people to try and find different ways to save time 
and effort when negotiating information and their social environment - which may also include media exposure (Fiske \& Taylor, 1984).

In terms of these assumptions, results of the current study suggest that when it comes to music, the contribution of narrative visuals may in fact decrease narrative engagement rather than encourage it. This finding rather challenges previous research which suggests that visuals, especially in combination with music, contribute to the narrative understanding of the narrative (as partial conceptualizations of narrative engagement; e.g., Boltz, 2004; Brechman, 2010, Marshall \& Cohen, 1988; Strick, de Bruin, de Ruiter, \& Jonkers, 2015). This argument also implies that the visuals in music videos are in fact narrative, but that they tell a different story than the story song-listeners personally attribute to the lyrics.

Recording artists - or communicators of pro-social or educational messages more generally - may make particular use of the effect that music video narratives can differ from the song narratives. Lady Gaga's song "Til It Happens to You" (2015), for example, by itself is about the notion that people have to experience something in order to fully understand it. The music video, however, is showing explicit rape scenes and portraying friendship as an empowering way to cope with the trauma of sexual assault. The meaning of the song lyrics becomes defined much more precisely in the context of the music video. The strong visuals and clear message may not even leave room for different interpretations of the lyrics, at least for people who hear the song for the first time through the music video. It can be argued that she purposefully employed the music video (as a popular, viral, and wide-reaching media form) to tell a less interpretative story of the song, starting her pro-social campaign to raise awareness of sexual assault and reduce victim-blaming.

\section{Limitations and Future Research}

As with most research various limitations with the sample, experimental setup, stimuli, and measurements should be considered when interpreting the data - many of which can also addressed in

future research. To begin with, the ecological nature of the controlled experimental environment, in which participants were surveyed, can be seen as a concern, as it fostered a particularly focused song listening 
experience, whereas recorded music naturally is consumed at the side while engaging in other activities, which is moving it to the background of attention and making natural music perception rather passively (Jaspersen, 2004).

With regard to the choice of stimulus material, it needs to be noted that whereas the music videos have been pilot-tested for narrativity scores, the song-neutral video has not. That is, some may argue that even though the visuals themselves do not narrate their own storyline, in combination with the lyrics and melody of the music, and being filmed from a first-person perspective, participants may have filled the musical plot with personal representations (in line with notions by Ryan, 2004). After all, it once more has to be stated that it is difficult to create a visual motion picture stimuli that is not inherently narrative in the given context of different presentations of songs, as people inevitably sense that songs tell a story, i.e. narrate (Vernallis, 2004). It further should be stated that the sample in this study consisted of college students only, presenting an overall rather young population. This may be a limitation as emotional reactions to narratives, appreciation in particular, may vary among different cognitive maturity levels (Gross et al., 1997; Lewis et al., 2014; Piaget, 1948).

The conceptualization of enjoyment and appreciation used in this study (based on Oliver \& Bartsch, 2010), representing different cognitive and affective systems, may be limiting the results and possibilities for interpretation. Other approaches have used these terms to differentiate between various types of needs, that may or may not be satisfied through media exposure (e.g., Vorderer, 2009; Oliver, 2008), with enjoyment satisfying needs such as pleasure and comprehension, and appreciation as the satisfaction of needs of authority, autonomy, and relatedness (Ryan \& Deci, 2000). The value in this needs-based approach in the context of music and music videos lies in their ability to uncover possible motives for consuming music videos in the first place. In fact, the current study was inspired by the notion that music videos re-gained popularity, but not (only) as marketing tools, but as valuable tools to communicate the artist's view of the song (music videos as visualizations of the song narrative), and as a tool to communicate pro-social message (in the sense of entertainment education). Along these lines, future research may evaluate the potential of music videos to communicate persuasive educational 
messages, by comparing narrative processing between music videos and songs alone, representing the comprehension (or recall) of messages contained. A future line of research on levels of narrative comprehension could further reinforce the notion that narrative music video visuals may disrupt or contradict the mental images people create from listening to the song, possible resulting in a reduction of levels of narrative engagement. 


\section{CONCLUSION}

Overall, the current research suggests that previous findings on the mental processes of narrative transportation and experiences of narrative engagement only partially apply when it comes to presentations of songs through audio-visual media. The experience of being swept up in a narrated world, as a consequence of listening to or watching music, did increase levels of enjoyment and appreciation. However, the experience of transportation and engagement itself was enjoyable and appreciated, not the song presentation per se. Data disconfirms a mediating effect of narrative experiences between different presentations of songs and levels of enjoyment and appreciation. What is more, the visualization of song narratives, as in music videos, seems to disrupt narrative engagement processes with the song. That is, music videos seem to be perceived as a different media experience, detached from the song itself, with an inherently different narrative than the song by itself. That is, when responding to song experiences, people do not seem to consider music videos as a song experience. These findings contradict theoretical notions that music videos are a secondary product that serves the song experience through cinematic elements. The current study rather shows how the uniquely combined media modalities of music videos can change the experience of, and psychological responses to, the song narrative. The visualization does not foster an inherently more transporting and engaging experience than experiencing the song narrative in its purest form - through listening to the song alone. 


\section{B I B L I O G R A P H Y}

Abbott, H. (2002). The Cambridge Introduction to Narrative. Cambridge: Cambridge University Press.

Adorno, T. W. (1992). Mahler: A musical physiognomy. Chicago: University of Chicago Press. (original work published 1960)

Appel, M., Gnambs, T., \& Maio, G. R. (2012). A short measure of the need for affect. Journal of Personality Assessment, 94, 418-426. doi:10.1080/00223891.2012.666921

Aufderheide, P. (1986), Music Videos: The Look of the Sound. Journal of Communication, 36, 57-78. doi:10.1111/j.1460-2466.1986.tb03039.x

Bartsch, A., Vorderer, P., Mangold, R., \& Viehoff, R. (2008). Appraisal of emotions in media use: Toward a process model of meta-emotion and emotion regulation. Media Psychology, 11, 7-27. doi:10.1080/15213260701813447

Beyoncé (2013). "Self-Titled": Part 1, The Visual Album. Retrieved from: https://www.youtube.com/watch?v=IcN6Ke2V-rQ

Bergeron, V., \& Lopes, D. M. (2009). Hearing and seeing musical expression. Philosophy and Phenomenological Research, 78, 1-16. doi:10.1111/j.1933-1592.2008.00230.x

Bilandzic, H., \& Busselle, R. W. (2011). Enjoyment of films as a function of narrative experience, perceived realism and transportability. Communications: The European Journal of Communication Research, 36, 29-50. doi:10.1515/COMM.2011.002

Boltz, M. G. (2004). The cognitive processing of film and musical soundtracks. Memory \& Cognition, 32, 1194-1205. doi:10.3758/BF03196892

Brechman, J. (2010). "Narrative "Flow": A model of narrative processing and its impact on information processing, knowledge acquisition and persuasion. Retrieved from ProQuest Digital Dissertations. (AAI3447502)

Busselle, R., \& Bilandzic, H. (2008). Fictionality and perceived realism in experiencing stories: A model of narrative comprehension and engagement. Communication Theory, 18, 
255-280. doi:10.1111/j.1468-2885.2008.00322.x

Busselle, R., \& Bilandzic, H. (2009). Measuring narrative engagement. Media Psychology, 12, 321-347. doi:10.1080/15213260903287259

Raney, A. A., \& Bryant, J. (2002). Moral judgment and crime drama: An integrated theory of Enjoyment. Journal of Communication, 52, 402-415. doi:10.1111/j.1460-2466.2002.tb02552.x

Cacioppo, J. T., Petty, R. E., \& Kao, C. F. (1984). The efficient assessment of need for cognition. Journal of Personality Assessment, 48, 306-307. doi:10.1207/s15327752jpa4803_13

Cohen, J. (1988). Statistical power analysis for the behavioral sciences. Hillsdale, NJ: Lawrence Erlbaum Associates.

Cromie, W. J. (1998). Music Videos Promote Adolescent Aggression. The Harvard University Gazette. Retrieved from: http://news.harvard.edu/gazette/1998/04.09/MusicVideosProm.html

Cutietta, R.(1985). Using Rock Music Videos to Your Advantage. Music Educators Journal 71, 47-49. doi: $10.2307 / 3396475$

Childs, B.. (1977). Time and Music: A Composer's View. Perspectives of New Music, 15, 194-219. http://doi.org/10.2307/832819

Ellis, E. S. (2013). Preference between audio-visual recorded performance and audio-only recorded performance. Retrieved from: http://search.proquest.com/docview/1436258798?accountid=2837

Englis, B. G. (1991). Music Television and its Influences on Consumer Culture, and the Transmission of Consumption Messages. In: R. H. Holman, \& M. R. Solomon (Eds.), Advances in Consumer Research (pp.111-114). Provo, UT : Association for Consumer Research.

Faul, F., Erdfelder, E., Buchner, A., \& Lang, A. (2009). Statistical power analyses using G*Power 3.1: Tests for correlation and regression analyses. Behavior Research Methods, 41, 1149-1160. doi:10.3758/BRM.41.4.1149

Fiske, S. T., \& Taylor, S. E. (1984). Social cognition (1st ed.). Reading, MA: Addison-Wesley.

Fludernik, M. (1996). Towards a "Natural” Narratology. London: Routledge.

Fludernik, M. (2009). An Introduction to Narratology. London: Routledge. 
Frison, E., Vandenbosch, L., Trekels, J., \& Eggermont, S. (2015). Reciprocal relationships between music television exposure and adolescents' sexual behaviors: The role of perceived peer norms. Sex Roles, 72, 183-197. doi:10.1007/s11199-015-0454-4

Fry, D. L., \& Fry, V. H. (1987). Some structural characteristics of music television videos. The Southern Speech Communication Journal, 52. doi:10.1080/10417948709372685

Green, M. C., \& Brock, T. C. (2000). The role of transportation in the persuasiveness of public narratives. Journal of Personality and Social Psychology, 79, 701-721. doi:10.1037/0022-3514.79.5.701

Green, M. C., Brock, T. C., \& Kaufman, G. F. (2004). Understanding media enjoyment: The role of transportation into narrative worlds. Communication Theory, 14, 311-327. doi:10.1093/ct/14.4.311

Green, M. C., Brock, T.C., \& Livingston, S.D. (2004) The need for entertainment scale. In L. J. Shrum (Ed.) Blurring the lines: The psychology of entertainment media (255-274). Mahwah, NJ: Lawrence Erlbaum Associates

Green, M. C., Kass, S., Carrey, J., Herzig, B., Feeney, R., \& Sabini, J. (2008). Transportation across media: Repeated exposure to print and film. Media Psychology, 11, 512-539. doi:10.1080/15213260802492000

Gross, J. J., Carstensen, L. C., Pasupathi, M., Tsai, J., Gottestam, K., \& Hsu, A. Y. C. (1997). Emotion and aging: Experience, expression, and control. Psychology and Aging, 12, 590-599 doi:10.1037//0882-7974.12.4.590.

Goto, M. (2007). Active music listening interfaces based on signal processing. Acoustics, Speech and Signal Processing, 4. doi:10.1109/ICASSP.2007.367351

Hall, A. E., \& Bracken, C. C. (2011). "I really liked that movie": Testing the relationship between trait empathy, transportation, perceived realism, and movie enjoyment. Journal of Media Psychology, 23, 90-99. doi:10.1027/1864-1105/a000036

Hayes, A. F. (2016). The PROCESS macro for SPSS and SAS. ProcessMacro.org. Retrieved from: http://www.processmacro.org/index.html 
Jaspersen, T. (2004). Tonträger. In: W. Faulstich (Ed.), Grundwissen Medien (pp. 385- 410). München: Wilhelm Fink Verlag.

Jones, S. (2011). Genre and Music Video: Configurations and Functions. In: D. Railton, \& P. Watson (Eds.), Music video and the politics of representation (pp. 41-66). Edinburgh: Edinburgh University Press.

Kaufman, G. (2015). These Five VMA Nominees Have An Important Message For You. Retrieved from http://www.mtv.com/news/2252988/vma-social-message-rihanna-big-sean/.

Kaplan, M. A. (1987). Rocking Around the Clock: Music Television, Postmodernism, and Consumer Culture. New York: Methuen.

Keazor, H. \& Wübbena, T. (2010). Rewind-Play-Fast Forward: The Past, Present and Future of the Music Video. Bielefeld: Transcript.

Keazor, H. (2011). “I had the strangest week ever!”. In: K. Kukkonen \& S. Klimek (Eds.), Metalepsis in Music Videos (pp. 104-127). New York: De Gruyter.

Lang, A. (2006). Using the limited capacity model of motivated mediated message processing to design effective cancer communication messages. Journal of Communication, 56, 57-80. doi:10.1111/j.1460-2466.2006.00283.x

Lewis, R. J., Tamborini, R., \& Weber, R. (2014). Testing a Dual-Process model of media enjoyment and appreciation. Journal of Communication, 64, 397-416. doi:10.1111/jcom.12101

Lipscomb, S. D., \& Kendall, R. A. (1994). Perceptual judgement of the relationship between musical and visual components in film. Psychomusicology, 13, 60. doi:10.1037/h0094101

Lynch, S. (2014). The Best Visual Artist-Directed Music Videos of All Time. Retrieved from: http://www.complex.com/style/2014/02/the-best-artist-directed-music-videos/

Maio, G.R., \& Esses, V. M., (2001). The need for affect: Individual differences in the motivation to approach or avoid emotions. Journal of Personality, 69, 582-615. doi: 10.1111/14676494.694156

Marks, C., \& Tannenbaum, R. (2011). I want my MTV: The Uncensored Story of the Music Video 
Revolution. New York: Dutton.

Marshall, S. K., \& Cohen, A. J. (1988). Effects of musical soundtracks on attitudes toward animated geometric figures. Music Perception: An Interdisciplinary Journal, 6, 95-112. doi: $10.2307 / 40285417$

Maus, F. E. (1991). Music As Narrative. Indiana Theory Review, 12, 1-34. Retrieved from http://www.jstor.org/stable/24045349

McPherson, G. E. \& Thompson, W. F. (1998). Assessing music performance: Issues and influences. Research Studies in Music Education, 10, 12-24. doi:10.1177/1321103X9801000102

Middleton, R. (1990). Studying Popular Music. Buckingham: Open University Press.

Micznik, V. (2001). Music and narrative revisited: Degrees of narrativity in Beethoven and Mahler. Journal of the Royal Musical Association, 126, 193-249. doi:10.1093/jrma/126.2.193

Moore, A. F. (2012). Song Means: Analysing and Interpreting Recorded Popular Song. Surrey: Ashgate Publishing.

Music Video. (2015). In Encyclopaedia Britannica. Retrieved from http://academic.eb.com/EBchecked/topic/399088/music-video

Nabi, R. L., \& Krcmar, M. (2004). Conceptualizing media enjoyment as attitude: Implications for mass media effects research. Communication Theory, 14, 288-310. doi:10.1093/ct/14.4.288

Nabi, R. L., \& Oliver, M. B. (2009).The SAGE handbook of media processes and effects. Los Angeles: SAGE.

Nattiez, J.-J. (1990). Music and Discourse: Toward a Semiology of Music. Princeton: Princeton University Press.

Nicholls, D. (2007). Narrative theory as an analytical tool in the study of popular music texts. Music \& Letters, 88(2), 297-315. doi:10.1093/ml/gcm006

Oliver, M. B., \& Bartsch, A. (2010). Appreciation as audience response: Exploring entertainment gratifications beyond hedonism. Human Communication Research, 36, 53-81. doi:10.1111/j.1468-2958.2009.01368.x 
Oliver, M. B., Bowman, N. D., Woolley, J. K., Rogers, R., Sherrick, B. I., \& Chung, M.-Y. (2015). Video games as meaningful entertainment experiences. Psychology of Popular Media Culture. Retrieved from http://psycnet.apa.org/psycinfo/2015-14534-001/

Oliver, M. B., \& Raney, A. A. (2011). Entertainment as pleasurable and meaningful: Identifying hedonic and eudaimonic motivations for entertainment consumption. Journal of Communication, 61, 984 1004. doi:10.1111/j.1460-2466.2011.01585.x

Petchers, B. (2014). What to expect from Music Videos in 2014. Retrieved from: http://www.forbes.com/sites/brianpetchers/2014/02/19/what-to-expect-from-music-videos-in2014/

Piaget, J. (1948). The moral judgment of the child. Glencoe, IL: The Free Press

Platz, F., \& Kopiez, R. (2012). When the eye listens: A meta-analysis of how audio-visual presentation enhances the appreciation of music performance. Music Perception: An Interdisciplinary Journal, 30, 71-83. doi:10.1525/MP.2012.30.1.71

Pasler, J. (1989). Narrative and Narrativity. In: J. T. Fraser (Ed.), Time and Mind: Interdisciplinary Issues (pp. 233 - 257). International Universities Press.

Parr, C. (2006). The importance of music videos. Retrieved from: http://www.artistshousemusic.org/videos/chris+parr+on+the+importance+of +music+vide

Railton, D., \& Watson, P. (2011). Music video and the politics of representation. Edinburgh: Edinburgh University Press.

Ranta, M. (2013). (Re-)creating order: Narrativity and implied world views in pictures. Storyworlds: A Journal of Narrative Studies, 5, 1-30. doi:10.5250/storyworlds.5.2013.0001

Ryan, M.-L. (2005). Narrative. In: D. Herman, M. Jahn, \& M.-L. Ryan (Eds.). Routledge Encyclopedia of Narrative Theory (pp. 344-348). London: Routledge.

Ryan, R. M., \& Deci, E. L. (2000). Self-determination theory and the facilitation of intrinsic motivation, social development, and well-being. American Psychologist, 55, 68. doi:10.1037/0003066X.55.1.68. 
Ryan, M.-L. (2004). Narrative across media: The languages of storytelling. Lincoln: University of Nebraska Press.

Sherman, B. L., \& Dominick, J. K. (1986). Violence and Sex in Music Videos: TV and Rock'n’Roll. Journal of Communication, 36, 79-93. doi:10.1111/j.1460-2466.1986.tb03040.x

Strick, M., de Bruin, H. L., de Ruiter, L. C., \& Jonkers, W. (2015). Striking the right chord: Moving music increases psychological transportation and behavioral intentions. Journal of Experimental Psychology. Applied, 21, 57-72. doi:10.1037/xap0000034

Smith, C. (2015). By the Numbers: 120 Amazing YouTube Statistics. Retrieved from: http://expandedramblings.com/index.php/youtube-statistics/

Soto-Sanfiel, M. T. (2015). Engagement in mobile listening. Retrieved from: https://pdfs.semanticscholar.org/9088/683fe350254158550a5aea524f636efec4db.pdf

Swallow, J. (2003). Dark eye - The Films of David Fincher. London: Reynolds \& Hearn.

Thompson, W., Graham, P., \& Russo, F. (2005). Seeing music performance: Visual influences on perception and experience. Semiotica, 156, 203-227. doi:10.1515/semi.2005.2005.156.203

Van Laer, T., de Ruyter, K., Visconti, L. M., \& Wetzels, M. (2014). The extended transportation-imagery model: A meta-analysis of the antecedents and consequences of consumers' narrative transportation. Journal of Consumer Research, 40, 797-817. doi:10.1086/673383

Vernallis, C. (2004). Experiencing music video: Aesthetics and cultural context. New York: Columbia University Press.

Vorderer, P., Klimmt, C., \& Ritterfeld, U. (2004). Enjoyment: At the heart of media entertainment. Communication Theory, 14, 388-408. doi:10.1093/ct/14.4.388

Vorderer, P. (2009). What do we want when we want narratives? Retrieved from http://sites.google.com/a/newliteracies.co.cc/xin-su-yang-yan-jiu-qun/2009shu-wei-xu-shi-guo-jigong-zuo-fang/1-2-vorderer

Wallis, C. (2011). Performing gender: A content analysis of gender display in music videos. Sex Roles, 64, 160-172. doi:10.1007/s11199-010-9814-2 


\section{A P P E N D I X A}

\section{Table 1}

List of Pilot-Tested Music Video / Song Stimuli

\begin{tabular}{|c|c|c|c|c|c|}
\hline Rec. Artist & Song Title & Length & $\begin{array}{l}\text { Number } \\
\text { of Views }\end{array}$ & $\begin{array}{l}\text { Narr. } \\
\text { score }\end{array}$ & YouTube Link \\
\hline Shura & Indecision* & $3: 35$ & 525,846 & 5.60 & http://bit.ly/1xZDCJ8 \\
\hline SOAK & Reckless Behavior* & $3: 12$ & 141,315 & 6.80 & http://bit.ly/1ODN0FN \\
\hline Crystal Fighters & Champion Sound* & $3: 55$ & $2,651,913$ & 5.50 & http://bit.ly/1MeWVTS \\
\hline Wolf Alice & Moaning Lisa Smile* & $2: 48$ & $2,422,445$ & 5.75 & http://bit.ly/1obctv6 \\
\hline Band of Horses & Is there a Ghost & $3: 00$ & $6,159,200$ & 5.00 & http://bit.ly/1k6a8Ep \\
\hline Cults & You Know What I Mean* & $2: 58$ & $1,003,195$ & 5.00 & http://bit.ly/1kDJA9k \\
\hline The Black keys & Tighten up & $3: 59$ & $57,492,169$ & 5.60 & http://bit.ly/1e0QsfM \\
\hline Wolf Alice & Bros & $3: 46$ & $2,424,658$ & 5.60 & http://bit.ly/1FRU4hh \\
\hline St. Vincent & Cruel & $3: 17$ & $3,688,844$ & 4.60 & http://bit.ly/1gDC1Lw \\
\hline
\end{tabular}

Note: $*=0 \%$ familiarity among pilot sample (music video, artist, song); number of views $=$ worldwide views on YouTube only, as of may 2016; : Narr. score = narrative score given in pilot test;

\section{Table 2}

Stimulus Matrix

Song Experimental Condition

\begin{tabular}{llll}
\cline { 2 - 4 } & Song Only & Music Video & Song-Neutral Video \\
\hline Song 1 & Condition 1a & Condition 2a & Condition 3a \\
Song 2 & Condition 1b & Condition 2b & Condition 3b \\
Song 3 & Condition 1c & Condition 2c & Condition 3c \\
\hline
\end{tabular}


Table 3

ANCOVA: Narrative Transportation and Narrative Engagement across Conditions with covariates

\begin{tabular}{lcccccc} 
& \multicolumn{3}{c}{ Narrative Transportation } & \multicolumn{3}{c}{ Narrative Engagement } \\
\cline { 2 - 7 } & $F$ & $p$ & $\eta 2$ & $F$ & $p$ & $\eta 2$ \\
\hline Transportability & 3.718 & .056 & .033 & .095 & .759 & .001 \\
Need for Cognition & 7.480 & $.007^{*}$ & .064 & 2.154 & .145 & .019 \\
Need for Affect & 6.685 & $.011^{*}$ & .058 & 1.793 & .183 & .016 \\
Level of Boredom & 6.364 & $.013^{*}$ & .055 & 7.727 & $.006^{*}$ & .066 \\
Level of Stress & 4.338 & $.040^{*}$ & .038 & .399 & .529 & .004 \\
Song Condition & .919 & .402 & .017 & 3.334 & $.039^{*}$ & .058 \\
\hline
\end{tabular}

Note. ${ }^{*}=p<.05, * * *=p<.001$.

\section{Table 4}

ANOVA: Narrative Transportation and Narrative Engagement across Conditions (without Covariates)

\begin{tabular}{lcccccc} 
& \multicolumn{3}{c}{ Narrative Transportation } & \multicolumn{3}{c}{ Narrative Engagement } \\
\cline { 2 - 7 } & $F$ & $p$ & $\eta 2$ & $F$ & $p$ & $\eta 2$ \\
\hline Song Condition & 1.748 & .179 & .030 & 4.804 & $.010^{*}$ & .078 \\
\hline
\end{tabular}

Note. $*=p<.05, * * *=p<.001$.

Table 5

Linear Regression: Narrative Transportation (Model A) and Narrative Engagement (Model B) across Enjoyment Scores

Enjoyment

\begin{tabular}{lllllllll}
$t$ & $B$ & $F$ & $d f 1$ & $d f 2$ & $p$ & Adj.R2 R2 Change \\
\hline
\end{tabular}

$\begin{array}{lllllllll}\text { Narrative Transportation } & 4.84 & .41 & 23.39 & 1 & 115 & .000^{* * *} & .16 & .17 \\ \text { Narrative Engagement } & 9.58 & .67 & 91.77 & 1 & 115 & .000^{* * *} & .44 & .44\end{array}$

Note. ${ }^{*}=p<.05, * * *=p<.001$. 
Table 6

Multiple Regression: Narrative Transportation (Model A) and Narrative Engagement (Model B) across Enjoyment Scores with Co-Variates

\begin{tabular}{|c|c|c|c|c|c|c|c|c|c|}
\hline & & & Enj & oyment & & & & & \\
\hline & $t$ & $p$ & B & $F$ & $d f 1$ & $d f 2$ & $p$ & $\operatorname{Adj.R2}$ & R2 Change \\
\hline Model A & & & & 5.07 & 6 & 110 & $.000 * * *$ & .18 & .14 \\
\hline Transportability & 1.786 & .077 & .164 & & & & & & \\
\hline Need for Cognition & -.868 & .387 & -.081 & & & & & & \\
\hline Need for Affect & .703 & .483 & .065 & & & & & & \\
\hline Level of Boredom & -.107 & .915 & -.010 & & & & & & \\
\hline Level of Stress & -1.222 & .224 & -.112 & & & & & & \\
\hline Narrative Transp. & 4.490 & $.000 * * *$ & .422 & & & & & & \\
\hline Model B & & & & 16.29 & 6 & 110 & $.000^{* * *}$ & .44 & .40 \\
\hline Transportability & .915 & .362 & .068 & & & & & & \\
\hline Need for Cognition & -1.027 & .307 & -.077 & & & & & & \\
\hline Need for Affect & 1.073 & .286 & .079 & & & & & & \\
\hline Level of Boredom & 1.148 & .254 & .091 & & & & & & \\
\hline Level of Stress & -1.096 & .275 & -.081 & & & & & & \\
\hline Narrative Eng. & 9.087 & $.000 * * *$ & .670 & & & & & & \\
\hline
\end{tabular}

Note. $*=p<.05, * * *=p<.001$.

\section{Table 7}

Pearson Correlations between Narrative Transportation, Enjoyment, and five Co-Variates

\begin{tabular}{lrrrrrrr}
\hline \multicolumn{1}{c}{ Variable } & \multicolumn{1}{c}{ 1 } & \multicolumn{1}{c}{ 2 } & \multicolumn{1}{c}{ 3 } & \multicolumn{1}{c}{5} & \multicolumn{1}{c}{ 6 } & \multicolumn{1}{c}{7} \\
\hline 1. Enjoyment & - & .072 & -.119 & $.175^{*}$ & -.113 & -.082 & $.411^{* * *}$ \\
2. Transportability & .072 & - & $.276^{*}$ & $.232^{*}$ & .028 & .030 & $-.190^{*}$ \\
3. Need for Cognition & -.119 & $.276^{*}$ & - & $.168^{*}$ & $-.196^{*}$ & -.003 & $-.227^{*}$ \\
4. Need for Affect & $.175^{*}$ & $.232^{*}$ & $.168^{*}$ & - & $-.178^{*}$ & $-.154^{*}$ & $.158^{*}$ \\
5. Level of Boredom & -.113 & .028 & $-.196^{*}$ & $-.178^{*}$ & - & $.317^{* * *}$ & $-.181^{*}$ \\
6. Level of Stress & -.082 & .030 & -.003 & $-.154^{*}$ & $.317^{* * *}$ & - & .092 \\
7. Narrative Transp. & $.411^{* * *}$ & $-.190^{*}$ & $-.227^{*}$ & $.158^{*}$ & $-.181^{*}$ & .092 & - \\
\hline
\end{tabular}

Note. $*=p<.05, * * *=p<.001$. 


\section{Table 8}

Pearson Correlations between Narrative Engagement, Enjoyment, and five Co-Variates

\begin{tabular}{|c|c|c|c|c|c|c|c|}
\hline Variable & 1 & 2 & 3 & 4 & 5 & 6 & 7 \\
\hline 1. Enjoyment & - & .072 & -.119 & $.175^{*}$ & -.113 & -.082 & $.666^{* * *}$ \\
\hline 2. Transportability & .072 & - & $.276^{*}$ & $.232 *$ & .028 & .030 & .011 \\
\hline 3. Need for Cognition & -.119 & $.276^{*}$ & - & $.168^{*}$ & $-.196^{*}$ & -.003 & -.083 \\
\hline 4. Need for Affect & $.175^{*}$ & $.232 *$ & $.168^{*}$ & - & $-.178^{*}$ & $-.154 *$ & .143 \\
\hline 5. Level of Boredom & -.113 & .028 & $-.196^{*}$ & $-.178^{*}$ & 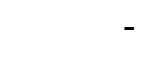 & $.317 * * *$ & $-.270 *$ \\
\hline 6. Level of Stress & -.082 & .030 & -.003 & $-.154 *$ & $.317 * * *$ & & -.029 \\
\hline 7. Narrative Eng. & $.666 * * *$ & .011 & -.083 & $.143 *$ & -.270 & -.029 & - \\
\hline
\end{tabular}

Note. $*=p<.05, * * *=p<.001$

Table 9

Linear Regression: Narrative Transportation (Model A) and Narrative Engagement (Model B) across Appreciation Scores

Appreciation

\begin{tabular}{lccccccccc} 
& \multicolumn{10}{c}{ Appreciation } \\
\cline { 2 - 9 } & $t$ & $\beta$ & $F$ & $d f 1$ & $d f 2$ & $p$ & Adj.R2 & R2 Change \\
\hline & & & & & & & & \\
Narrative Transportation & 5.65 & .47 & 31.93 & 1 & 115 & $.000^{* * *}$ & .21 & .22 \\
Narrative Engagement & 11.26 & .72 & 126.77 & 1 & 115 & $.000^{* * *}$ & .52 & .52 \\
& & & & & & & & \\
\hline Note. $*=p<.05, * * *=p<.001$. & & & & & & &
\end{tabular}




\section{Table 10}

Multiple Regression: Narrative Transportation (Model A) and Narrative Engagement (Model B) across Appreciation Scores, with Co-Variates

Appreciation

\begin{tabular}{|c|c|c|c|c|c|c|c|c|c|}
\hline \multirow{2}{*}{ Variable } & \multicolumn{7}{|c|}{ Appreciation } & \multirow{2}{*}{\multicolumn{2}{|c|}{ Adj.R2 R2 Change }} \\
\hline & $t$ & $p$ & $\beta$ & $F$ & $d f 1$ & $d f 2$ & $p$ & & \\
\hline Model A & & & & 6.50 & 6 & 110 & $.000 * * *$ & .15 & .14 \\
\hline Transportability & .969 & .335 & .086 & & & & & & \\
\hline Need for Cognition & -.416 & .678 & -.038 & & & & & & \\
\hline Need for Affect & 1.513 & .133 & .135 & & & & & & \\
\hline Level of Boredom & -1.312 & .192 & -.121 & & & & & & \\
\hline Level of Stress & .225 & .823 & .020 & & & & & & \\
\hline Narrative Transp. & 4.698 & $.000 * * *$ & .429 & & & & & & \\
\hline Model B & & & & 21.96 & 6 & 110 & $.000 * * *$ & .52 & .43 \\
\hline Transportability & -.170 & .865 & -.012 & & & & & & \\
\hline Need for Cognition & -.441 & .660 & -.031 & & & & & & \\
\hline Need for Affect & 2.155 & $.033 *$ & .148 & & & & & & \\
\hline Level of Boredom & -.179 & .859 & -.013 & & & & & & \\
\hline Level of Stress & .731 & .467 & .050 & & & & & & \\
\hline Narrative Eng. & 10.221 & $.000 * * *$ & .698 & & & & & & \\
\hline
\end{tabular}

Note. $*=p<.05, * * *=p<.001$.

\section{Table 11}

Pearson Correlations between Narrative Transportation, Appreciation, and five Co-Variates

\begin{tabular}{lrrrrrrr}
\hline \multicolumn{1}{c}{ Variable } & 1 & \multicolumn{2}{c}{ 2 } & \multicolumn{1}{c}{3} & \multicolumn{1}{c}{4} & \multicolumn{1}{c}{5} & \multicolumn{1}{c}{7} \\
\hline 1. Appreciation & - & .023 & -.065 & $.235^{*}$ & $-.206^{*}$ & .003 & $.466^{* * *}$ \\
2. Transportability & .023 & - & $.276^{*}$ & $.232^{*}$ & .028 & .030 & $-.190^{*}$ \\
3. Need for Cognition & -.065 & $.276^{*}$ & - & $.168^{*}$ & $-.196^{*}$ & -.003 & $-.227^{*}$ \\
4. Need for Affect & $.235^{*}$ & $.232^{*}$ & $.168^{*}$ & - & $-.178^{*}$ & $-.154^{*}$ & $.158^{*}$ \\
5. Level of Boredom & $-.206^{*}$ & .028 & $-.196^{*}$ & $-.178^{*}$ & $-.317^{* *}$ & $-.181^{*}$ \\
6. Level of Stress & .003 & .030 & -.003 & $-.154^{*}$ & $.317^{* * *}$ & - & .092 \\
7. Narrative Transp. & $.466^{* * *}$ & $-.190^{*}$ & $-.227^{*}$ & $.158^{*}$ & $-.181^{*}$ & .092 & - \\
\hline
\end{tabular}

Note. $*=p<.05, * * *=p<.001$. 


\section{Table 12}

Pearson Correlations between Narrative Engagement, Appreciation, and five Co-Variates

\begin{tabular}{lrrrrrrr}
\hline \multicolumn{1}{c}{ Variable } & \multicolumn{1}{c}{ 1 } & \multicolumn{1}{c}{3} & \multicolumn{1}{c}{4} & \multicolumn{1}{c}{5} & \multicolumn{1}{c}{. } \\
\hline 1. Appreciation & - & .023 & -.065 & $.235^{*}$ & $-.206^{*}$ & .003 & $.724 * * *$ \\
2. Transportability & .023 & - & $.276^{*}$ & $.232^{*}$ & .028 & .030 & .011 \\
3. Need for Cognition & -.065 & $.276^{*}$ & - & $.168^{*}$ & $-.196^{*}$ & -.003 & -.083 \\
4. Need for Affect & $.235^{*}$ & $.232^{*}$ & $.168^{*}$ & - & $-.178^{*}$ & $-.154^{*}$ & .143 \\
5. Level of Boredom & $-.206^{*}$ & .028 & $-.196 *$ & $-.178^{*}$ & - & $.317 * * *$ & $-.270^{*}$ \\
6. Level of Stress & -.003 & .030 & -.003 & $-.154^{*}$ & $.317 * * *$ & - & -.029 \\
7. Narrative Eng. & $.724 * * *$ & .011 & -.083 & $.143^{*}$ & -.270 & -.029 & - \\
\hline
\end{tabular}

Note. $*=p<.05, * * *=p<.001$. 
A P P E N D I X B

PILOT TEST SURVEY 


\section{Consent Form}

Thanks so much for showing interest in my study!

My study is on music and media use. In this short survey, I am interested in learning more about your thoughts and feelings about three different music videos.

This study can be completed online, and I don't expect the session to last more than 20 minutes. I recommend that you complete the survey on a desktop or laptop PC and have either headphones or speakers plugged in - possibly in private so that you don't disturb anyone and so they don't disturb you while listening.

Your participation in this research is completely confidential, meaning that all of your responses will be kept secured and given the highest legal protection. Your responses will only be used as a manipulation check for my study, and will not be published or shared in any way.

Thank you in advance for your time, and for your valuable contribution to my research project!

Sincerely,

Lea M. Schlue

M.A. Student / Graduate Teaching Assistant

Department of Communication Studies

Eberly College of Arts \& Sciences, West Virginia University

leschlue@mix.wvu.edu 


\section{Audio Test}

In the following, you will be asked to listen to some music =) ! However, before you start, please test your internet connection and make sure that your audio is working.

Please hit the "Play" button below, and listen to this short track. If you don't hear any music, please double-check your audio settings - is everything turned on and working properly? If you are still having audio problems, then you will be unable to complete the survey.

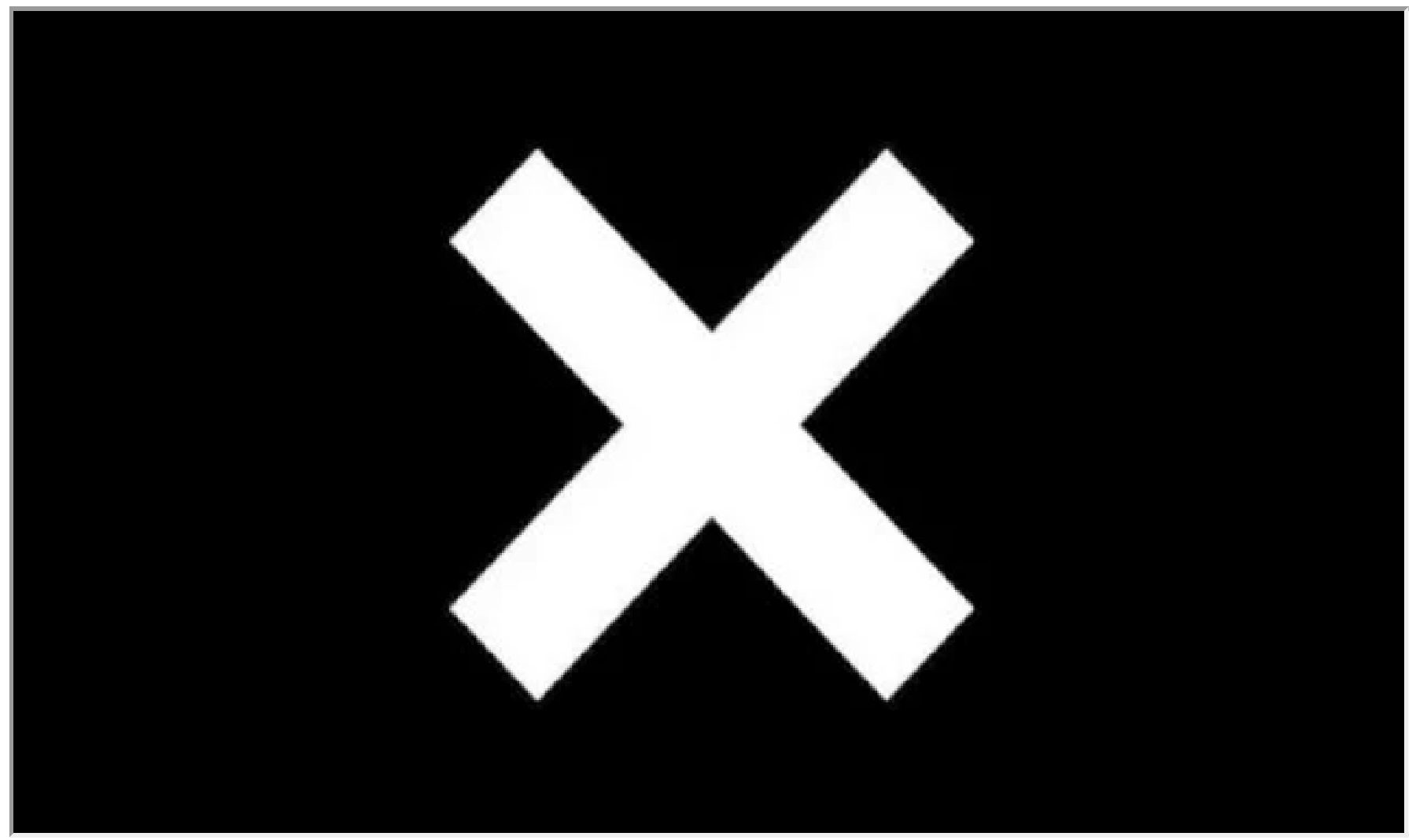

When you are ready, click the "NEXT" button and follow the the instructions on that screen to play the music.

Okay - it seems like everything is working! I will now show you three different random music videos (there are questions in between the music videos). Please try to avoid any distractions in order to pay full attention to the music. For example, 
you could put headphones on if you have a pair handy. We appreciate your cooperation - thank you, and enjoy!

When you are ready, click the "NEXT" button and follow the the instructions on that screen to play the music.

\section{Stimulus 1 / Shura}

Please watch the music video below, in its entirety. To start, click on the play button displayed. Once the song is over, please click the "NEXT" button to continue the survey.

NOTE: The song might take a few seconds to start playing - this is completely normal.

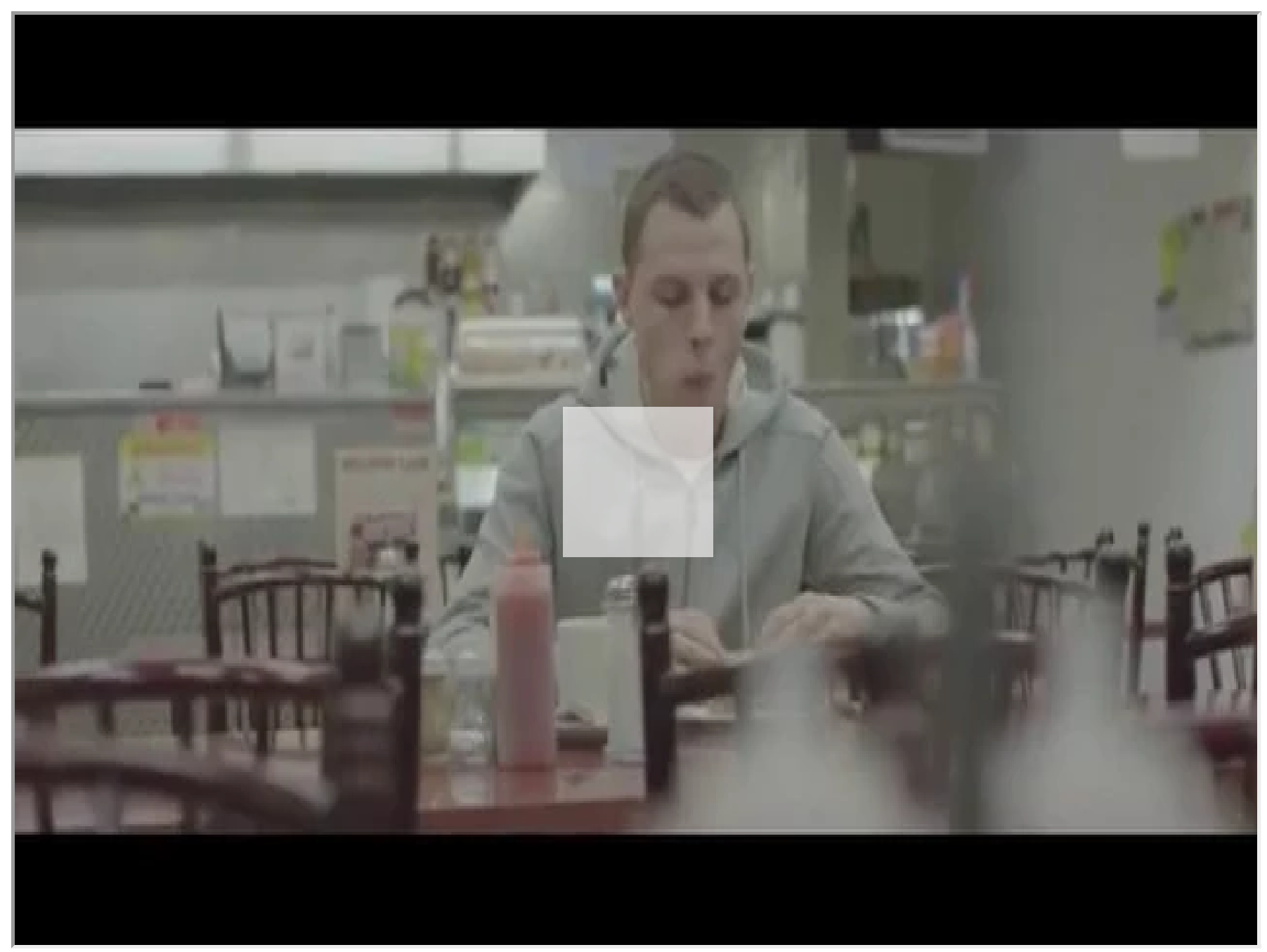


Artist / Song

Shura / Indecision

Please name three adjectives describing this song / music video (e.g. cheerful, or sad, etc.).

How would you describe the genre of this song / music video (rock, hip-hop, pop, etc.) ?

How would you rate the quality of the music video?

very bad

Video quality
0

bad

0

O ok

$\mathrm{O}$

$\mathrm{O}$ good

0

0 very good

0

O

In the following, please provide how much you enjoyed and appreciated the music video.

Thanks for filling this out! =)

$\begin{array}{lccc} & \text { Neither } \\ \text { agree } & & \\ \text { Strongly } & \text { Somewhat } & \text { nor } & \text { Somewhat } \\ \text { disagree Disagree disagree disagree agree } & \text { Agree } & \text { Strongly } \\ \text { agree }\end{array}$


The music video was entertaining.

O

0

0

0

0

O

I found this

music video

aesthetically

O

0

0

0

0

strong.

I found the music video artistically

valuable.

I know I will

never forget this

O

0

0

$\mathrm{O}$

0

O

music video.

The music video left me with a lasting

O

0

0

$\mathrm{O}$

0

O

impression.

The music video was thought-

$0 \quad 0$

0

0

0

provoking.

I found this

music video to

be very

O

0

0

O

O

meaningful.

This music video will stick with me for a long time.

$0 \quad 0$

0

0

0

$\mathrm{O}$

It was fun for me to watch this music video.

$\begin{array}{lllllll}0 & 0 & 0 & 0 & 0 & 0 & 0\end{array}$

This music video is a cinematic

O

O

$\mathrm{O}$

O

masterpiece.

I was at the

edge of my seat

while watching

$\mathrm{O} \quad \mathrm{O}$

O

$\mathrm{O}$

O

this music video.

The music video was

O

0

$\mathrm{O}$

$\mathrm{O}$

$\mathrm{O}$

0

suspenseful.

I was moved by

this music video.

O $0 \quad 0$

0

$\mathrm{O}$

0

O

I had a good 
time watching this music video.

O $=0$

$\mathrm{O}$

0

$\mathrm{O}$

This was a heart-pounding kind of music

$\begin{array}{lllllll}0 & 0 & 0 & 0 & 0 & 0 & 0\end{array}$ video.

In your own words, can you please describe what you enjoyed about this song / music video?

In your own words, can you please describe what you appreciated about this song / music video?

"A narrative is a representation or account of experiences, events, or the likes. It can be true or fictitious, it is usually (but not exclusively) told in great detail, and it is designed to amuse, interest, or instruct."

Based on this description - would you say that the music video you just watched is a narrative?

(This really is about your individual perception. There is no right or wrong answer.)

Strongly disagree

Disagree 

Somewhat disagree
Neither agree nor disagree
Somewhat agree
Agree
Strongly agree

This is the final set of questions about this music video. Please tell me about your familiarity with the song / music video you just listened to.

Yes No I don't remember.

Have you ever watched the music video for this song

$\mathrm{O}$

$\mathrm{O}$

$\mathrm{O}$

before?

Have you ever

listened to this song

$\mathrm{O}$

$\mathrm{O}$

$\bigcirc$

before?

Have you ever

listened to this artist before?

$\mathrm{O}$

$\mathrm{O}$

O

Thank you so much for providing your thoughts about this music video - I highly value your help!

\section{Stimulus 2 / SOAK}

Please watch the music video below in its entirety. To start, click on the play button displayed. Once the song is over, please click the "NEXT" button to continue the survey.

NOTE: The song might take a few seconds to start playing - this is completely normal. 
SURVEY PART 1 


\section{Consent Form}

\section{Thanks so much for showing interest in our study!}

You are being asked to participate in study conducted by researchers in the Department of Communication Studies at West Virginia University. This study is about music and media use. In particular, we are interested in learning more about your thoughts and feelings when listening to music.

If you agree to participate in our study, you will be asked about your experience when listening to music. The first part of this study can be completed entirely online, and we don't expect the session to last more than 10 minutes. At the end of the online survey, you will be asked to sign up and schedule for a 15-20 minute session in the Interaction Lab in Armstrong Hall (210E) at West Virginia University. In the Lab, you will be asked to listen to music and you'll be asked to respond with some typed answers.

In order to participate, you must be 18 years of age or older.

Your participation in this research is completely confidential, meaning that all of your responses will be kept secured and given the highest legal protection. Your responses will be used only for the purposes of this study, and will not be shared outside of our research team (the two individuals listed at the bottom of this document). Of course, you may skip any question(s) that you do not care to answer, or feel uncomfortable answering.

Participation in this study is voluntary. Unless otherwise indicated, you may skip certain questions if you want, and/or you may stop completing the questionnaire at any time without penalty. If you are a student at or employee of either West 
Virginia University, your actual performance in this study or your refusal to participate or withdrawal from this study will in no way affect your class standing, grades, job status, or status in any activity associated with either University.

Notably given that our study is on popular music, there is the chance that the content of our song might contain material that is offensive or disturbing to somes audiences. Notably, none of these songs have any explicit language or content warnings attached to them. If at any time you feel any discomfort resulting from your participation, we encourage you to contact the WVU Carruth Center at (304) 393-4431 for any counseling needs. If you have other concerns about the study itself, you may contact the WVU Office of Research Integrity and Compliance at (304) 293-7073.

In the laboratory session: If you would like more information about this research project, feel free to contact the WVU Principal Investigator, Dr. Bowman, at Nicholas.Bowman@mail.wvu.edu or (304) 293-3905 - if you are in the Morgantown, WV, area, he is also located in 210L Armstrong Hall on the WVU Downtown Campus. This study has been acknowledged by West Virginia University's Institutional Review Board, and is on file as Protocol \#1602018917. You are also encouraged to print a copy of this page for your personal records; you may also request a copy of this information by contacting Lea M. Schlue.

Thank you in advance for your time, and for your valuable contribution to our project!

Sincerely,

Lea M. Schlue

M.A. Student / Graduate Teaching Assistant

Department of Communication Studies

Eberly College of Arts \& Sciences, West Virginia University leschlue@mix.wvu.edu

Nicholas David Bowman, PhD (faculty advisor) 
Associate Professor of Communication Studies

Research Associate, Interaction Lab (\#ixlab)

Eberly College of Arts \& Sciences, West Virginia University

Nicholas.Bowman@mail.wvu.edu

I have read the document above, and I agree to participate in this study.

I have read the document above, and I do not agree to participate in this study.

\section{Warm-Up Questions}

To begin with, we would like to know about some of the music that you might listen to. From the list below, please use the options provided to tell us how much you like or dislike the following genres of music.

\begin{tabular}{|c|c|c|c|c|c|c|}
\hline & $\begin{array}{c}\text { Strongly } \\
\text { dislike }\end{array}$ & Dislike & $\begin{array}{l}\text { Slightly } \\
\text { dislike }\end{array}$ & $\begin{array}{l}\text { Neither } \\
\text { dislike } \\
\text { nor like }\end{array}$ & $\begin{array}{l}\text { Slightly } \\
\text { like }\end{array}$ & Like \\
\hline Rock & $\mathrm{O}$ & $\mathrm{O}$ & $\mathrm{O}$ & $\mathrm{O}$ & $\mathrm{O}$ & $\mathrm{C}$ \\
\hline Folk & 0 & 0 & O & 0 & $\mathrm{O}$ & \\
\hline Jazz & 0 & 0 & 0 & 0 & O & \\
\hline Pop & & & O & ) & 0 & \\
\hline$R \& B$ & $\mathrm{O}$ & $\mathrm{O}$ & $\mathrm{O}$ & $\mathrm{O}$ & $\mathrm{O}$ & \\
\hline Hip-Hop/Rap & $\Omega$ & C & $\mathrm{O}$ & $\mathrm{O}$ & $\mathrm{O}$ & \\
\hline Electronic/House/Techo & $\mathrm{O}$ & $\mathrm{O}$ & $\mathrm{O}$ & $\mathrm{O}$ & $\mathrm{O}$ & \\
\hline Classical & $\Omega$ & $\Omega$ & 0 & $\mathrm{O}$ & O & \\
\hline Country & 0 & $\mathrm{O}$ & O & $\mathrm{O}$ & $\mathrm{O}$ & 0 \\
\hline Other & & & & & & \\
\hline
\end{tabular}

The next questions will ask you about the amount of time you spend listening to music during an average week. For each day of the week (starting with Sunday), please tell us how many hours and minutes on average you spend listening to music on that day. 
NOTE: If you listen to less than an hour of music on a day, please type in a " 0 " under the Hours column. For example, if you listen to music for 45 minutes on Tuesdays, then you would type in "0" for Hours and "45" for Minutes.

\begin{tabular}{lll|} 
& Hours \\
Sunday & \\
Monday & \\
Tuesday & \\
Wednesday & \\
Thursday & \\
Friday & \\
\hline
\end{tabular}

For these questions, we would like to estimate how much time you spend watching music videos on a daily basis. You can answer these questions just like the ones above - by typing in your answers as minutes or hours.

NOTE: If you listen to less than an hour of music on a day, please type in a " 0 " under the Hours column. For example, if you listen to music for 45 minutes on Tuesdays, then you would type in " 0 " for Hours and "45" for Minutes.

Sunday
Monday
Tuesday
Wednesday
Thursday
Friday
Saturday

\section{Trait Measures}


Think for a moment about watching your favorite television show or movie, listening to your favorite music, reading your favorite book, or playing your favorite video game. Please answer the following questions about those experiences, in general.

\begin{tabular}{|c|c|c|c|c|c|c|}
\hline & & & $\begin{array}{l}\text { Neither } \\
\text { agree }\end{array}$ & & & \\
\hline $\begin{array}{l}\text { Strongly } \\
\text { disagree }\end{array}$ & Disagree & $\begin{array}{c}\text { Somewhat } \\
\text { disagree }\end{array}$ & $\begin{array}{c}\text { nor } \\
\text { disagree }\end{array}$ & $\begin{array}{c}\text { Somewhat } \\
\text { agree }\end{array}$ & Agree & $\begin{array}{c}\text { Strongly } \\
\text { agree }\end{array}$ \\
\hline
\end{tabular}

I have vivid images of the

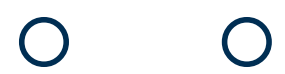

$\mathrm{O}$

O

O

0 characters.

I am often emotionally affected by what

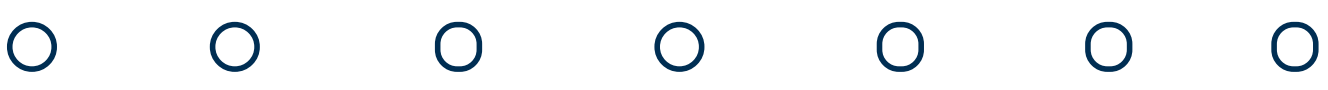

I've watched.

I sometimes feel as if I am part of the story.

I often find that reading stories has an impact on the way I see

$\mathrm{O}$

O

O

$\mathrm{O}$

0 things.

I can easily put stories out of my mind after l've finished

O

$0 \quad 0$

O

$\mathrm{O}$

watching them.

I easily identify with characters in the story.

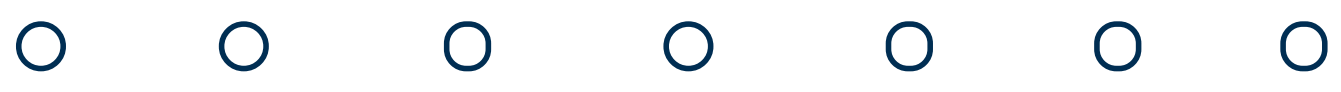

I can easily envision the events in the story.

I find myself feeling what the characters may feel.

I get mentally involved in the

$\begin{array}{lllllll}0 & 0 & 0 & 0 & 0 & 0 & 0\end{array}$ 
story.

I find myself

thinking of other ways the story

$0 \quad 0$

0

0

0

O

could have

ended.

I find it difficult

to tune out

activity around

O

0

0

$\mathrm{O}$

$0 \quad 0$

me.

I can easily envision myself

in the events

described in a

O

$\mathrm{O}$

0

0

0

$\mathrm{O}$

story.

I have vivid images of the events in the

$0 \quad 0$

O

0

O

0

$\mathrm{O}$

story.

I am often

impatient to find out how the

O

$\mathrm{O}$

$\mathrm{O}$

$\mathrm{O}$

O

story ends.

I find that I can

easily take the perspective of the character(s)

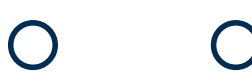

O

0

O

0

O

in the story.

I find that events

in the story are relevant to my

$\begin{array}{lllllll}0 & 0 & 0 & 0 & 0 & 0 & 0\end{array}$ everyday life.

I find I can easily lose myself in the story.

My mind often wanders.

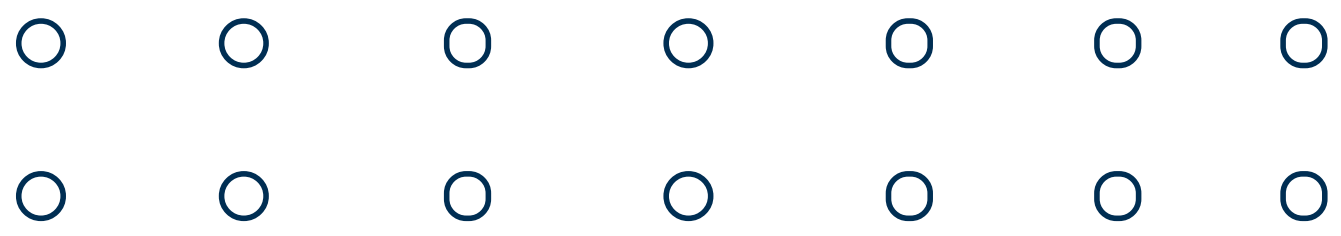

Thank you so much for your honesty and for staying with us, we appreciate your help. There are only a few questions to go, so let's please continue to the next page $=$ ). 
For each of the statements below, please indicate whether or not the statement is characteristic of you or of what you believe. For example, if the statement is extremely uncharacteristic of you or of what you believe about yourself (not at all like you) please indicate "Strongly disagree". If the statement is extremely characteristic of you or of what you believe about yourself (very much like you) please indicate "Strongly agree". Thank you!

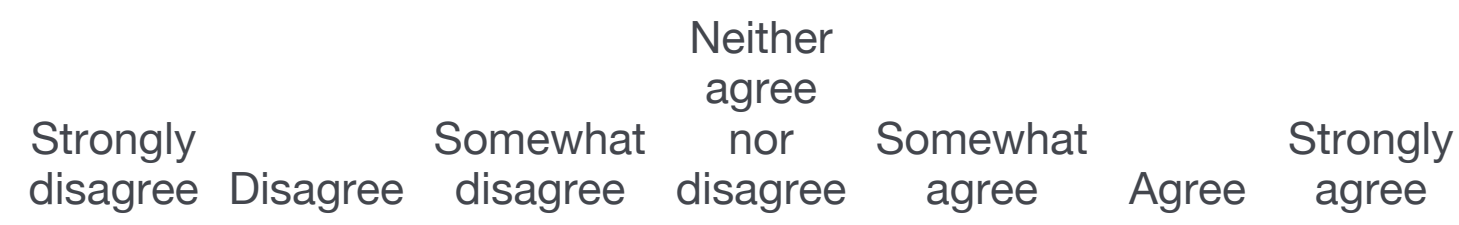

I would rather do something that requires little thought than something that

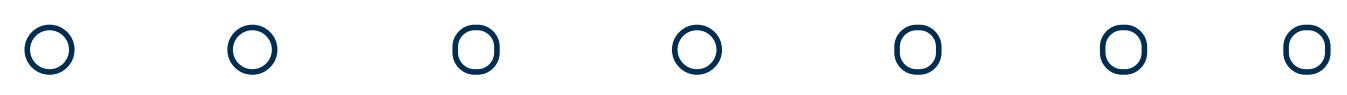
is sure to challenge my thinking abilities.

I prefer my life to be filled with puzzles I must solve.

It's enough for me that something gets the job done; I

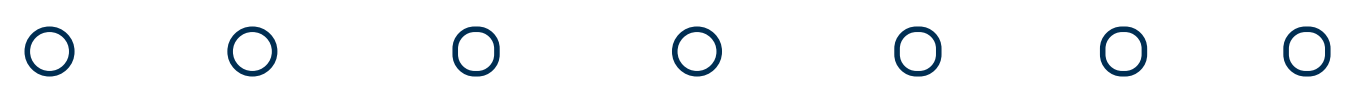
don't care how or why it works.

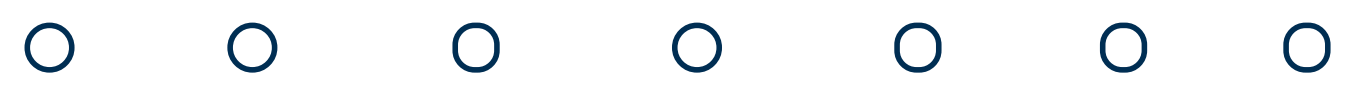

The notion of thinking abstractly is

$\begin{array}{lllllll}0 & 0 & 0 & 0 & 0 & 0 & 0\end{array}$ appealing to me.

I prefer to think about small daily projects to long

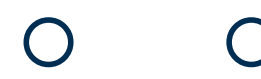

O

O

0

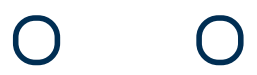
term ones.

I usually end up deliberating about issues even when they

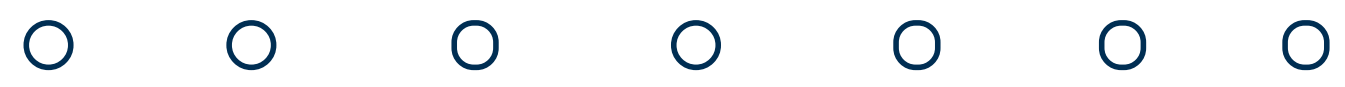
do not affect me personally. 
I would prefer a task that is intellectual, difficult, and important to one that is

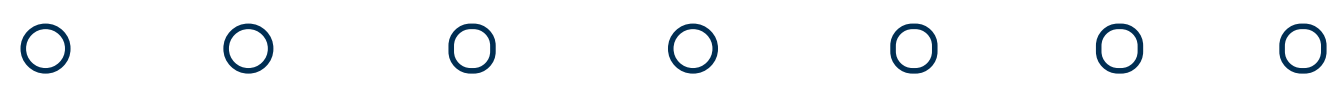

somewhat important but does not require much thought.

I like to have the responsibility of handling a situation that requires a lot of thinking.

I prefer complex to simple problems.

Thinking is not my idea of fun.
O 0
0
0
$\mathrm{O}$
O 0

I like tasks that require little thought once

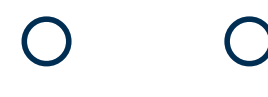

0

0

O

O

O

I've learned

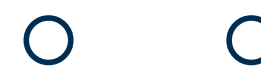

0

O

O

O

O

them.

I really enjoy a task that involves coming up with new

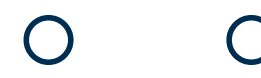

$\mathrm{O}$

0

$\mathrm{O}$

0

O solutions to problems.

I only think as hard as I have to.

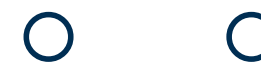

$\mathrm{O}$

$\mathrm{O}$

$\mathrm{O}$

O

$\mathrm{O}$

Learning new ways to think doesn't excite

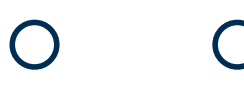

0

0

$\mathrm{O}$

0

O me very much.

I feel relief rather than satisfaction after completing a task that

O

0

O

$\mathrm{O}$

0

O requires a lot of mental effort.

I try to anticipate 
and avoid situations where there is a likely chance I will $\begin{array}{lllllll}0 & 0 & 0 & 0 & 0 & 0 & 0\end{array}$ have to think in depth about something.

I find satisfaction in deliberating hard and for

$\mathrm{O}$

O

$\mathrm{O}$

$\mathrm{O}$

$\mathrm{O}$

$\mathrm{O}$

O long hours.

The idea of relying on thought to make my way to the O O O $\mathrm{O}$

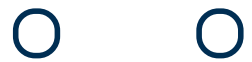
top appeals to me.

The following scale is about your individual approach to emotions. Again, these are about your personality, so there are no right or wrong answers.

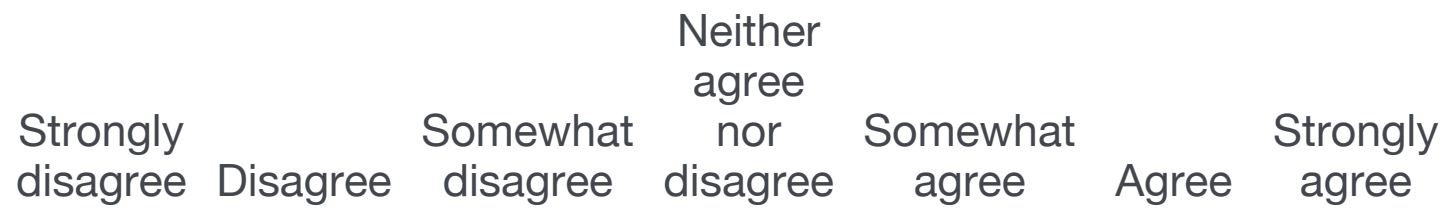

Displays of emotions are embarrassing.

$\mathrm{O}$

$\mathrm{O}$

$\mathrm{O}$

$\mathrm{O}$

O

$\mathrm{O}$

I like to dwell on my emotions.

$\mathrm{O}$

0

O

$\mathrm{O}$

0

O

Emotions help people get along

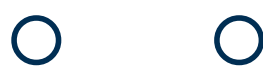

O

0

O

0

O in life.

I feel like I need a good cry every now and then.

I feel that I need to experience strong emotions regularly.

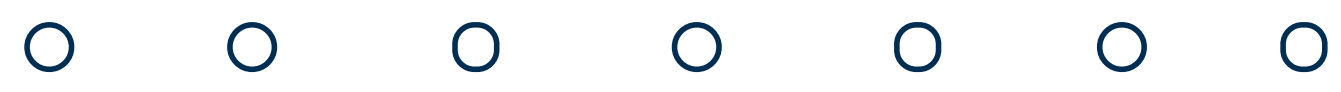

We should indulge our emotions.

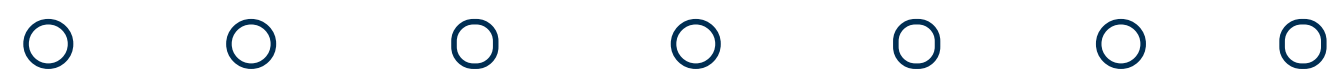


I find strong emotions overwhelming

$0 \quad 0 \quad 0$

$\mathrm{O}$

O

O and therefore try to avoid them.

I would prefer not to experience either O

0

O

0 the lows or highs of emotion.

I like decorating my bedroom with a lot of pictures and posters of things O<smiles>[O]</smiles><smiles>O</smiles>

$\mathrm{O}$<smiles>[O]</smiles>
emotionally significant to me.

I think that it is important to explore my<smiles>O</smiles><smiles>O</smiles>

$\mathrm{O}$

$\mathrm{O}$

$\mathrm{O}$

$\mathrm{O}$ feelings.

Emotions are dangerous - they tend to get me into situations

$\begin{array}{lllllll}0 & 0 & 0 & 0 & 0 & 0 & 0\end{array}$ that I would rather avoid.

I wish I could feel less emotion.

$\mathrm{O}$

O

$\mathrm{O}$

$\mathrm{O}$

$\mathrm{O}$

$\mathrm{O}$

$\mathrm{O}$

Strong emotions are generally beneficial.

O

$\mathrm{O}$

O

$\mathrm{O}$

0

O

Avoiding

emotional events helps me sleep

O

$\mathrm{O}$

O

$\mathrm{O}$

0

$\mathrm{O}$

better at night.

People can

function most

effectively when

they are not

$0 \quad 0 \quad 0$

$\mathrm{O}$

$\mathrm{O}$

$\mathrm{O}$

experiencing

strong emotions.

I do not know

how to handle

$\mathrm{O}$

$\mathrm{O}$

$\mathrm{O}$

$\mathrm{O}$

$\mathrm{O}$ 
my emotions, so

I avoid them.

It is important for me to know how others are

$\begin{array}{lllllll}0 & 0 & 0 & 0 & 0\end{array}$ feeling.

I am a very emotional person.

O

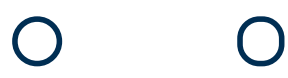

0

0

O

I approach

situations in

which I expect to

O

0

0

0

0

0

experience

strong emotions.

If I reflect on my past, I see that I tend to be afraid

00

0

0

0

0

of feeling

emotions.

I am sometimes

afraid of how I

might act if I

become too

00

0

0

0

0

emotional.

It is important for

me to be in

touch with my

O

0

0

0

O

feelings.

Acting on one's

emotions is

always a

00

0

0

0

0

0

mistake.

I have trouble

telling the people

close to me that

00

0

0

0

0

0

I love them.

The experience

of emotions

promotes human

0

0

0

0

0

0

0

\section{Demographics \& Completion}




\section{Final Section: Demographics}

Please enter the next page to finalize this survey and submit your answers. These are the final questions in the survey.

The following final questions reveal some personal information. Please indicate this information, as it is very valuable for our study. Of course, all information entered will be treated confidentially. Thank you for your your help!

Please type in your gender in the space below.

Please type in your ethnicity in the space below.

Please type in your age in the space below.

\section{Completion!}

Thank you for your completing the initial part of our study.

In addition, please enter your e-mail address below (before clicking "Next") so that we can confirm your survey and lab session time.

YourEmail@mix.wvu.edu

Click the "Next" button to submit your answers, and to be redirected to the 


\title{
scheduling page for the second part of our study.
}

\author{
Powered by Qualtrics
}


SURVEY PART 2 


\section{Audio Settings Test}

Thank you for participating in this study. This is the second and last part of the study. As a reminder, any information you provide in this study (including your responses here) will be kept confidential.

On each screen, please follow the instructions as followed. If you have any questions or experience any technical difficulties, please do not hesitate to ask - I will be in the room for the entire study.

Ready? If so, please click the "Next" button in the lower-right portion of the screen, and let's get started!

In this part of the study, we would like you to listen to some music =) !

Before you start, please make sure that the audio is working: Please hit the "Play" button below, and listen to this short track. If you do not hear any audio, please double-check to make sure that your audio settings are turned on, and that your audio input is working properly. If you are still having audio problems, please ask us for help. 


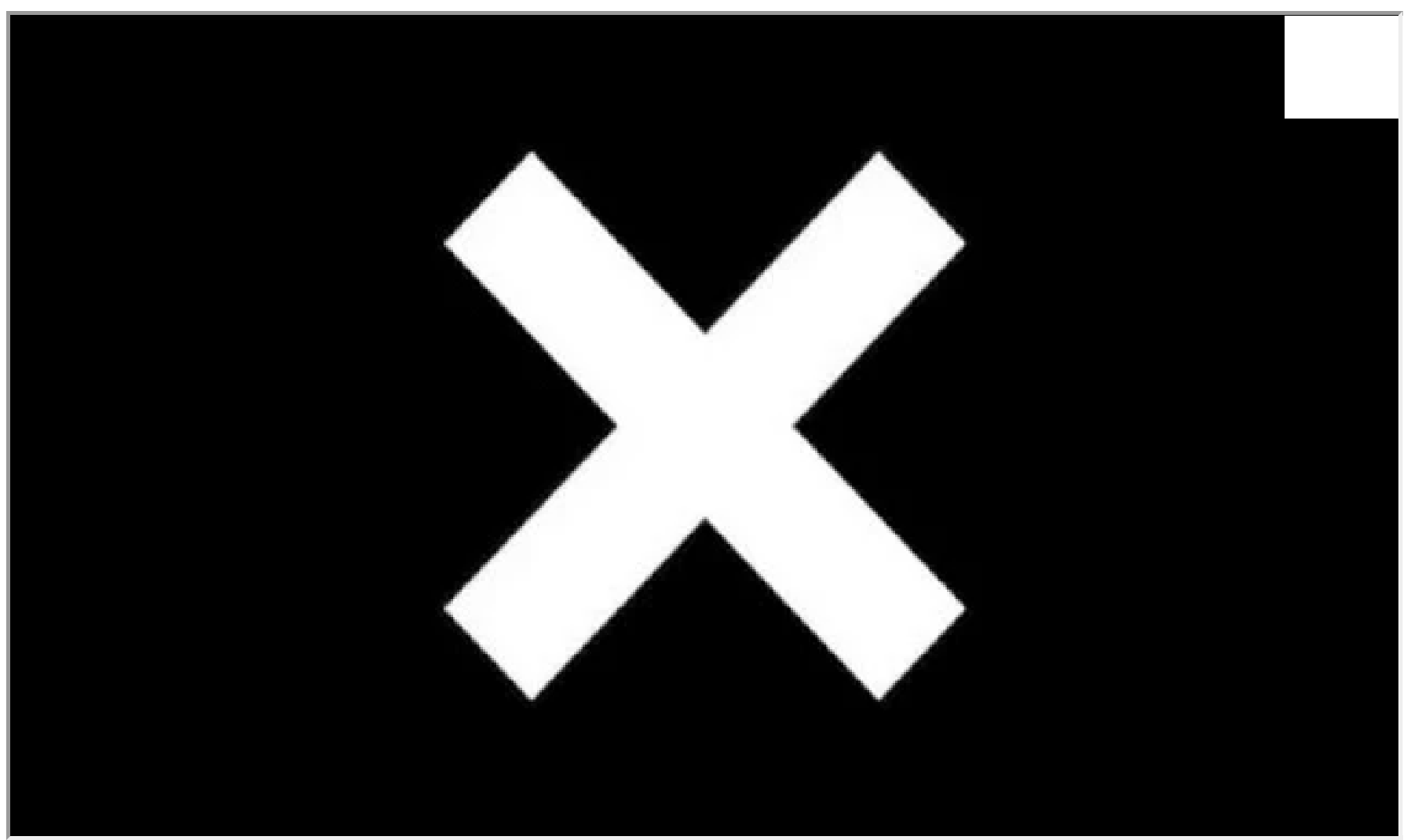

When you are ready, click the "NEXT" button and follow the the instructions on that screen to play the music.

\section{Stimulus: Crystal Fighters Original Video}

Okay - it seems like everything is working! We will now show you a random music video from our database. Try to avoid any distractions in order to pay full attention to the music. Thank you, and enjoy the song!

When you are ready, click the "NEXT" button and follow the the instructions on that screen to play the music.

Now, please watch the music video below, in its entirety. To start the song, click on the play button displayed. Once the song is over, please click the "NEXT" button to continue the survey.

NOTE: The song might take as many as 30 second to start playing - this is 
completely normal and part of the video.

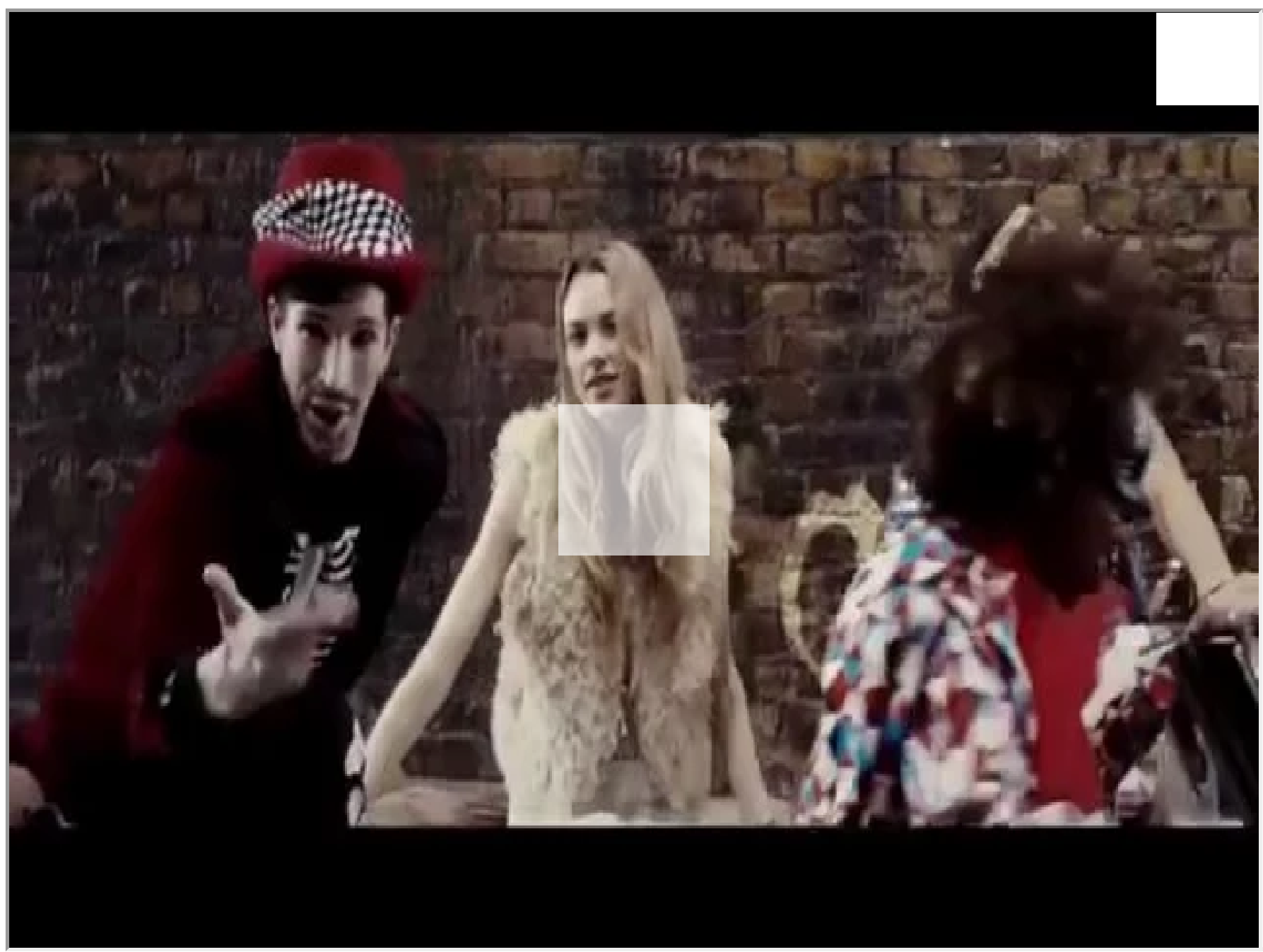

Please think about the music video you just watched, and answer the following questions about your experience.

$\begin{array}{ccccc} & \text { Neither } & & \\ \text { Strongly } & \text { Slightly } & \text { disagree } & \text { Slightly } & \text { Strongly } \\ \text { disagree Disagree disagree } & \text { or Agree } & \text { agree } & \text { Agree } & \text { Agree }\end{array}$

My understanding of the characters is

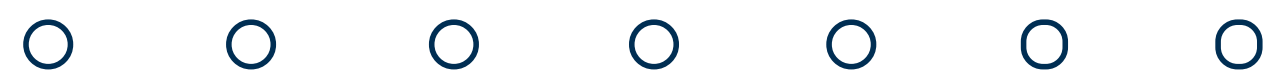
unclear.

I felt sorry for some of the characters in the song.

I had a hard time keeping my mind on

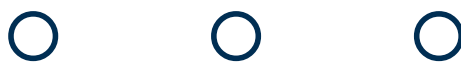

O

$\bigcirc$

$\mathrm{O}$

$\mathrm{O}$

$\mathrm{O}$ 
the song.

During the song, my body was in the room, but my mind was inside the

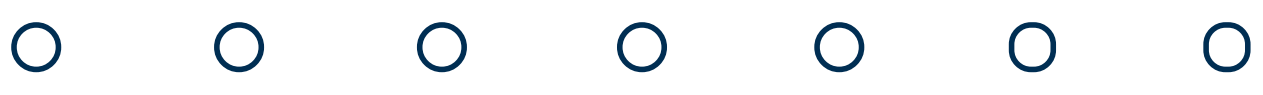
world created by the story.

The story affected me emotionally.

$\mathrm{O}$

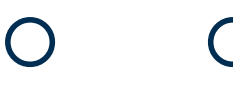

O

$\mathrm{O}$

0

$\mathrm{O}$

At points, I had a hard time making sense of what was
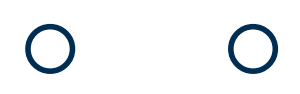

0

0

O

0

O

going on in the song.

I found my mind wandering while the O

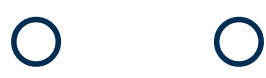

O

$\mathrm{O}$

O

O song was playing.

The song created a new world, and then that world suddenly

O

0

0

O

0

O disappeared when the program ended.

At times during the song, the story world was closer to

O

$O$

$\mathrm{O}$

0

O

$\mathrm{O}$ me than the real world.

During the song, when a main character succeeded, I felt happy, and when

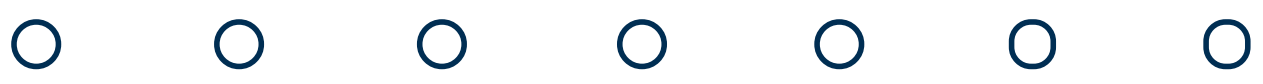
they suffered in some way, I felt sad.

While the song was playing, I found myself thinking

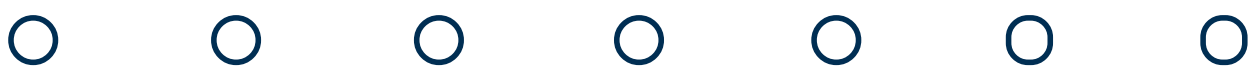
about other things.

I had a hard time recognizing the thread of the story.

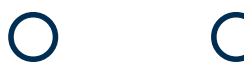

$\mathrm{O}$

$\mathrm{O}$

$\mathrm{O}$

O

0 
The following questions may seem similar to those on the previous page.

However, they are highly valuable for the study so please fill out the following scale just as thoughtfully as the previous scale.

Neither

$\begin{array}{lccc}\text { Strongly } & \text { Slightly disagree } & \text { Slightly } & \text { Strongly } \\ \text { disagree Disagree disagree or Agree agree Agree } & \text { agree }\end{array}$

While I was watching the music video, I could easily picture the events in it taking O

O

O

O place.

While I was watching the music video, activity going on in the room around me was on my mind.

I could picture myself in the scene of the events shown in the music video.

I was mentally involved in the music video while watching it.

After finishing the music video, I found it easy to put it out of
$0 \quad 0$
O
0
0
0
0 my mind.

I wanted to learn how the music video ended.

The music video affected me emotionally.
O
0
0
0
0
0

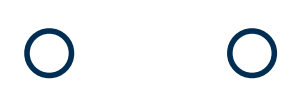

0

0

0

0

I found myself

thinking of ways the music video could O

$\begin{array}{llllll}0 & 0 & 0 & 0 & 0\end{array}$

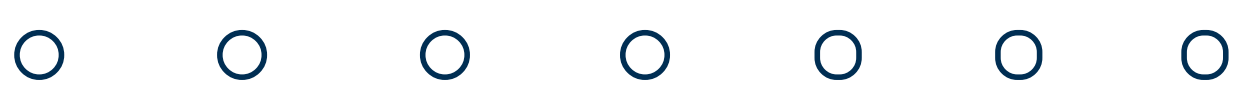
have turned out differently.

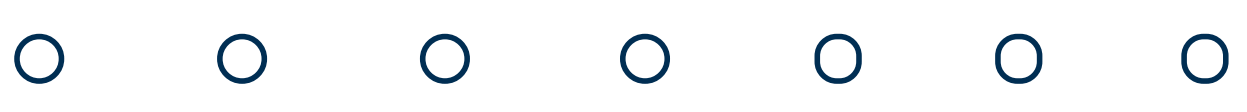

I found my mind wandering while watching the music

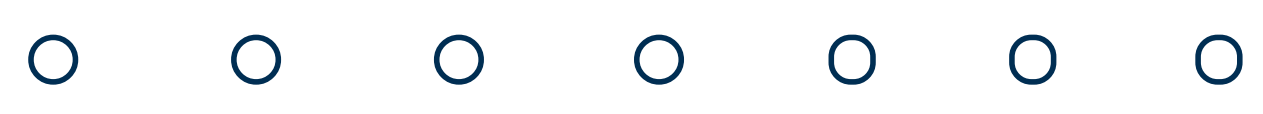


video.

The events in the music video are relevant to my
O
O
$\mathrm{O}$
$\mathrm{O}$
$\mathrm{O}$
$\mathrm{O}$
O
$\begin{array}{lllllll}0 & 0 & 0 & 0 & 0 & 0 & 0\end{array}$

everyday life.

The events in the music video have changed my life.

Thank you so much for your honesty and for keeping it rolling, we appreciate your help. There are only a few questions to go, so let's please continue to the next page $=$ ).

"A narrative is a representation or account of experiences, events, or the likes. It can be true or fictitious, it is usually (but not exclusively) told in great detail, and it is designed to amuse, interest, or instruct."

Based on this description - would you say that the music video you just watched is a narrative?

(This really is about your individual perception. There is no right or wrong answer.)

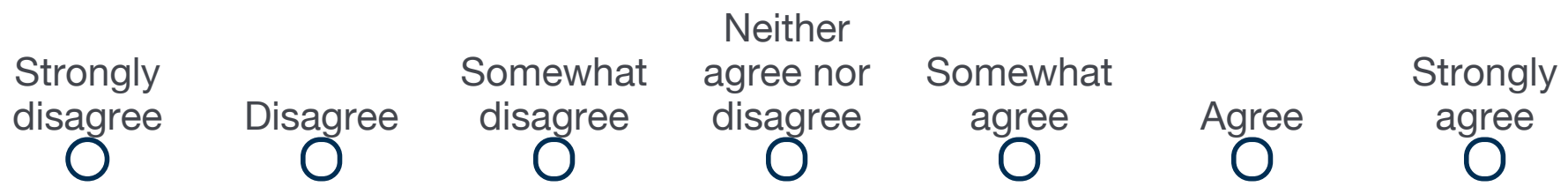

In your own words, can you please describe what you think the song is about? (Again: This really is about your individual perception. There is no right or wrong answer.) 


\section{Audience Response}

You are getting closer to the end of the survey, so thanks so much for following this through. $=$ )

The following items ask about your reactions to the music as a whole. Please read each statement, and respond using the scale provided.

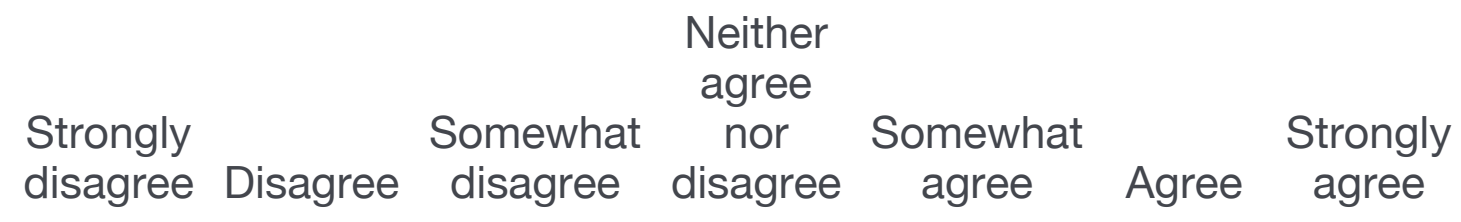

This was a

heart-pounding kind of song.

The song left me with a lasting impression.

It was fun for me to listen to this song.

I had a good time listening to this song.

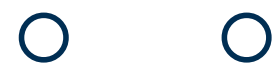

O

O

O

$\mathrm{O}$

O

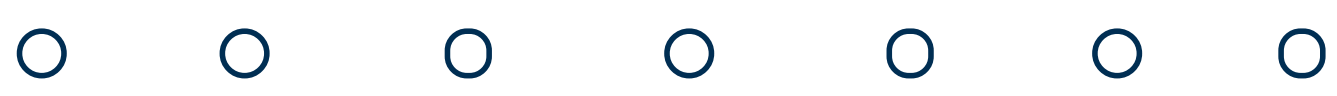

$\begin{array}{lllllll}0 & 0 & 0 & 0 & 0 & 0 & 0\end{array}$

This song will stick with me for a long time.

I was moved by this song.

The song was entertaining.

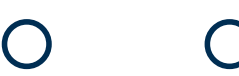

O

O

O

0

O

The song was

thought-

provoking.

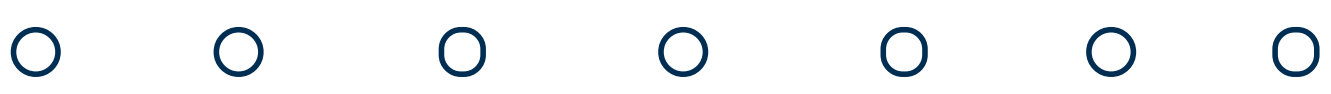

I know I will

never forget this song.

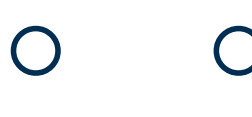

0

0

0

O

O

0

O

O

O

0

0

0

.

The song was suspenseful.

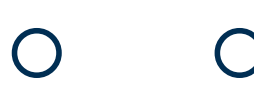

0

0

0

0

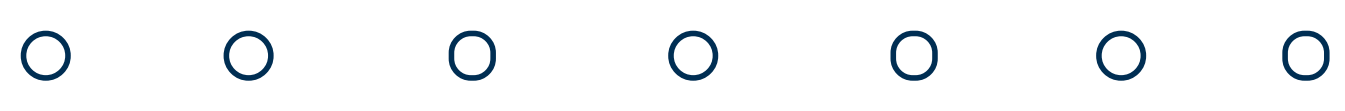


I found this song

O

Qualtrics Survey Software

aesthetically

strong.

I found this song to be very

meaningful.

$\begin{array}{lllllll}0 & 0 & 0 & 0 & 0 & 0 & 0\end{array}$

I was at the

edge of my seat

while listening to

O

0

O

O

0

O

this song.

This song is a

masterpiece.

$\mathrm{O} \quad \mathrm{O}$

O

$\mathrm{O}$

O

O

I found the song artistically

O

O

$\mathrm{O}$

$\mathrm{O}$

O valuable.

In your own words, can you please describe what you enjoyed about this song / music video?

In your own words, can you please describe what you appreciated about this song / music video?

State Transportability, Familarity with Music, Outro 
You are nearly there - this is the second-to-last question.

Let's be honest: Filling out a questionnaire like this can be somewhat energysapping. Please let us know how you feel right now!

\begin{tabular}{|c|c|c|c|c|c|c|c|}
\hline & $\begin{array}{l}\text { Strongly } \\
\text { disagree }\end{array}$ & Disagree & $\begin{array}{l}\text { Somewhat } \\
\text { disagree }\end{array}$ & $\begin{array}{c}\text { Neither } \\
\text { agree } \\
\text { nor } \\
\text { disagree }\end{array}$ & $\begin{array}{l}\text { Somewhat } \\
\text { agree }\end{array}$ & Agree & $\begin{array}{l}\text { Strongly } \\
\text { agree }\end{array}$ \\
\hline $\begin{array}{l}\text { I have felt bored } \\
\text { all day. }\end{array}$ & 0 & $\Omega$ & 0 & 0 & 0 & 0 & 0 \\
\hline $\begin{array}{l}\text { I feel bored right } \\
\text { now. }\end{array}$ & 0 & $\Omega$ & ค & & $\Omega$ & & \\
\hline $\begin{array}{l}\text { I have felt } \\
\text { stressed all day. }\end{array}$ & 0 & 0 & 0 & 0 & 0 & 0 & $\cap$ \\
\hline $\begin{array}{l}\text { I feel stressed } \\
\text { right now. }\end{array}$ & $\Omega$ & $\Omega$ & 0 & 0 & $\Omega$ & C & \\
\hline
\end{tabular}

Thank you so much for help. This is the last question of the survey! =)

Finally, please tell us about your familiarity with the music you listened to. Yes No I don't remember.

Have you ever watched the music video for this song

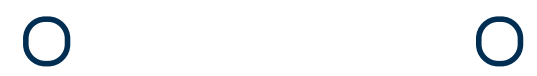

O before?

Have you ever listened to this song before?

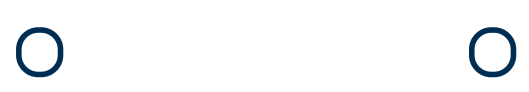

O

Have you ever listened to this artist before?

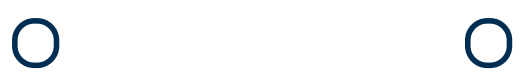

O

Please click the "NEXT" button and complete and submit this survey.

\section{It's a wrap!}


Thank you so much for completing both parts of this study. =)

This is very important: Please enter your e-mail address below (before clicking "Next") so that we can confirm your survey and lab session time.

name@mix.wvu.edu

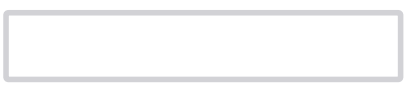

Powered by Qualtrics 